\title{
Aerogamaespectrometria e suas aplicações no mapeamento geológico
}

\author{
Vanessa Biondo Ribeiro \\ IAG/USP, Brasil \\ vanessa.ribeiro@usp.com \\ Marta S. M. Mantovani, \\ IAG/USP, Brasil \\ msmmanto@usp.br \\ Vinicius Hector Abud Louro, \\ IAG/USP, Brasil \\ vilouro@usp.br
}

\begin{abstract}
AEROGAMMASPECTROMETRY AND ITS APPLICATIONS IN GEOLOGICAL MAPPING. The substantial increase of geological information in recent years contributed a lot to understand the Brazilian mineral potential. However, much remains to be studied. The geophysics, based especially on potential methods and gamma-spectrometry, has wide applicability on delimiting geotectonic structures and on locating mineral exploration targets. In this work, we focus on interpreting the natural emission of gamma radiation detected on the surface associated to the main radioelements. To this, we presented a description of the main characteristics and data corrections used for an airborne survey. The interpretation of gamma-spectrometric data allows characterizing regions with undifferentiated lithological units, detecting the presence of outcropping igneous intrusions, hydrographic elements, hydrothermal alteration and/or intense erosive processes, contributing significantly on the understanding of a region. To illustrate the contribution, we present as case studies the analysis of data from the region of the Santa Helena Granitic Batholith (MT) and from the Alkaline-Carbonatite Complex of Tapira (MG).Citation: Ribeiro V.B., Mantovani M.S.M., Louro V.H.A. 2014. Aerogamaespectrometria e suas aplicações no mapeamento geológico. Terræ Didatica, 10(1):29-51. < http://www.ige.unicamp.br/terraedidatica/> .
\end{abstract}

KEYWORDS: Gamma ray spectrometry, aerial survey, interpretation of radiometric data.

RESUMO O aumento substancial de informações geológicas nos últimos anos contribuiu muito para o conhecimento do potencial mineral do Brasil. Entretanto, ainda há muito a ser estudado. A geofisica, especialmente baseada em métodos potenciais e gamaespectrométricos, tem grande aplicabilidade na delimitação de estruturas geotectônicas e na localização de alvos exploratórios minerais. Neste trabalho focalizamos a interpretação da emissão de radiação gama natural detectada na superficie associada aos principais radioelementos. Para tal, apresentamos uma descrição das características do aerolevantamento e das correções realizadas. A interpretação de dados gamaespectrométricos permite caracterizar regiões com unidades litológicas indivisas, detectar a presença de intrusões ígneas aflorantes, elementos hidrográficos, alteração hidrotermal e/ou intensos processos erosivos, contribuindo significativamente para o entendimento de uma região. Para ilustrar a contribuição, apresentamos como estudos de caso a análise de dados da região do Batólito Granítico de Santa Helena (MT) e do Complexo Alcalino-Carbonatítico de Tapira (MG).

PALAVRAS-CHAVES: Gamaespectrometria, aerolevantamento, interpretação de dados radiométricos. 


\section{Introdução}

A descoberta do elemento urânio é atribuída ao químico alemão Martin Klaproth, em 1789 (IAEA 2003). Em torno de 1855, o vidraceiro alemão Heinrich Geissler foi bem sucedido ao construir objetos de vidro contendo eletrodos de metal sob o vácuo, que poderiam ser usados para estudar a transmissão de cargas elétricas através do vácuo. Os raios catódicos que foram descobertos como resultado da experiência com tubos de Geissler receberam muita atenção dos físicos durante a segunda metade do século XIX (Faure 1997). Eles foram explicados em 1897 por J.J. Thomson como um fluxo de partículas carregadas negativamente (elétrons), constituindo um marco importante para a compreensão da estrutura interna dos átomos.

O físico alemão Wilhelm Conrad Röentgen estudou o fenômeno de luminescência nas paredes dos tubos de raios catódicos quando eram atravessados pelos raios. Röentgen descobriu que, se os tubos estivessem enrolados numa cartolina preta, eles causavam luminescência numa folha de papel que tinha uma película de platino-cianeto de bário. A luminescência continuava enquanto o tubo de raios catódicos mantinha-se energizado, mesmo se a folha de papel com a película fosse movida para um quarto adjacente. O relatório dessa descoberta foi apresentado em dezembro de 1895, e vários cientistas começaram a procurar uma conexão entre os raios-X de Röentgen e a luminescência.

A descoberta de Röentgen motivou Henri Becquerel a retomar seus trabalhos anteriores com os sais de urânio. Becquerel estava seguro de que os cristais de sulfato de uranila emitiam uma radiação invisível que penetrava o papel preto e velava as placas fotográficas sobre a qual eles estavam. Posteriormente, Becquerel determinou que os sais de urânio e mesmo os minerais que continham urânio, emitiam essa radiação continuamente sem tê-la que expor à luz do Sol. Essas descobertas foram apresentadas à Academia de Ciências em Paris em 1896 e tinham alcançado consequências que levaram nas décadas seguintes, ao desenvolvimento da física atômica e nuclear e da rádio química.

Diversos cientistas tiveram papel fundamental para o estudo da radioatividade, entre os quais podem ser citados: Marie e Pierre Curie (prêmio Nobel de Física em 1911), Rutherford (identificou as três componentes da radiação: $\alpha, \beta$ e $\gamma$ e, posteriormente o próton, em 1919), Frederick Soddy (junto com Rutherford desenvolveu a teoria do decaimento radioativo em 1900), F. Joliot e Sir J. Chadwick (identificaram a existência do nêutron), Niehls Bohr (modelo do átomo de hidrogênio), entre outros.

A descoberta da radioatividade foi rapidamente seguida pelo estudo de técnicas para medição desse fenômeno. Os primeiros detectores foram construídos no inicio do século XX e, posteriormente, surgiram os de instrumentos de campo portáteis. A sensibilidade dos sensores aumentou consideravelmente durante a década de 40 , com o desenvolvimento de cintilômetros.

A intensa exploração de urânio, principalmente para uso bélico, gerou a necessidade de pesquisas de novos depósitos desse mineral. Com esse intuito, as primeiras aquisições radiométricas aéreas foram realizadas no Canadá, EUA e antiga URSS em 1947, e na Austrália em 1951.

A espectrometria gama em laboratório, terrestre ou aérea começou a ser aplicada amplamente na exploração mineral e monitoramento ambiental principalmente entre os anos 60 e 70.

Entre as principais aplicações da gamaespectrometria podemos citar: identificação de pontos de afloramento de intrusões ígneas (Ribeiro et al. 2013), caracterização de intrusões indiferenciadas (Ulbrich et al. 2009), prospecção mineral (Fornazzari Neto e Ferreira 2003; Carrino et al. 2007), estudo de crateras de impacto (Vasconcelos et al. 2012), análise da influência de fertilizantes com derivados do urânio em rios e afluentes (Conceição e Bonotto, 2003), exploração petrolífera (Saunders et al. 1987; Lüning e Kolonic 2003; IAEA 2003), controle ambiental em áreas com vazamento radioativo (IAEA 2003), entre outros.

Apesar de existirem mais de 50 isótopos radioativos diferentes na natureza, a maioria é muito rara ou fracamente radioativa. Sendo assim, as principais fontes de radiação gama detectadas na superfície terrestre provêm da desintegração natural do potássio $\left({ }^{40} \mathrm{~K}\right)$ e dos elementos das séries do urânio $\left.{ }^{238} \mathrm{U}\right)$ e do tório $\left({ }^{232} \mathrm{Th}\right)$ presentes na composição da maioria das rochas (Cox 1979, Telford et al. 1990, Dickin 1995, Faure 1997).

A contagem total de radiação é obtida por intermédio de um espectrômetro, pela medida de todos os raios gama dentro da janela energética de 0,41 a 2,81 MeV. Neste intervalo, cada elemento é associado a um canal do espectrômetro onde as suas energias estão centradas: os raios gama emitidos pelo potássio $\left({ }^{40} \mathrm{~K}\right)$ se concentram no pico de energia de 1,46 MeV (Fig. 1 - Tabela 1). Os 


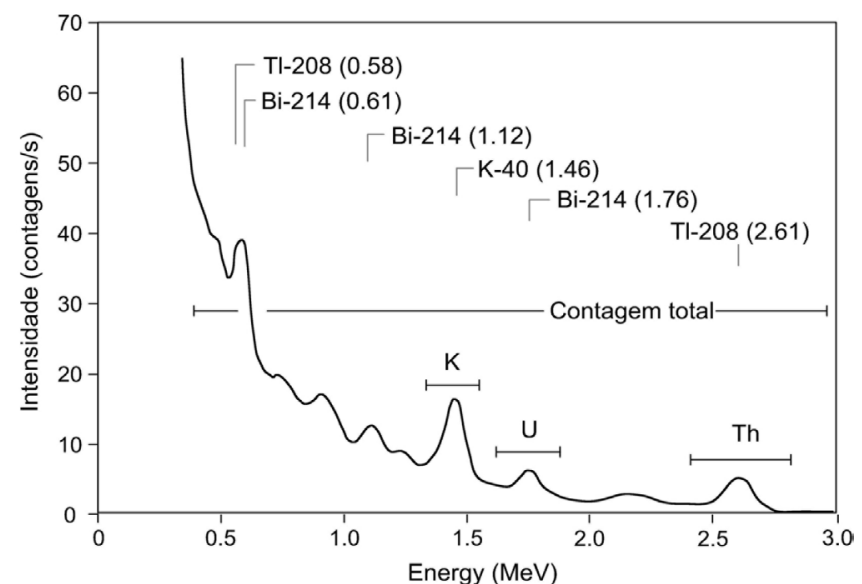

Figura 1. Espectros de radiação gama mostrando as posições da janela de energia para cada elemento e da contagem total (Modif. Foote 1968).

Tabela 1. Tabela com os valores dos canais e dos picos (em MeV) associados aos canais dos elementos radiométricos e à emissão cósmica. (Modif. IAEA 1993)

\begin{tabular}{c|c|c}
\hline Canal & $\begin{array}{c}\text { Faixa de Ener- } \\
\text { gia (Mev) }\end{array}$ & Pico (Mev) \\
\hline $\mathrm{K}^{40}$ & $1.37-1.57$ & 1.46 \\
\hline $\mathrm{U}^{238}$ & $1.66-1.86$ & 1.76 \\
\hline $\mathrm{Th}^{232}$ & $2.41-2.81$ & 2.61 \\
\hline $\mathrm{CT}$ & $0.41-2.81$ & - \\
\hline Cósmico & $3.0-8.0$ & - \\
\hline
\end{tabular}

isótopos ${ }^{238} \mathrm{U}$ e ${ }^{232} \mathrm{Th}$ não emitem radiação gama, porém seus produtos decorrentes do decaimento radioativo $\left({ }^{214} \mathrm{Bi}\right.$ e ${ }^{208} \mathrm{Tl}$, respectivamente) emitem raios gama com energias centradas em 1,76 e 2,61 $\mathrm{MeV}$ (Kaplan 1964). As estimativas das concentrações de urânio e tório geralmente são referidas na literatura como urânio equivalente (eU) e tório equivalente (eTh).

A radiação gama no solo é inversamente proporcional à densidade do meio que atravessa, sendo que qualquer matéria contida entre o emissor e o sensor pode afetar significativamente a detecção dos raios gama. Isto faz com que as medições radiométricas sejam essencialmente superficiais, tendo um alcance médio de 30 a $40 \mathrm{~cm}$ de profundidade (Minty 1988).

Entre os principais fatores que influenciam as medidas, pode-se citar:

- cobertura de solo ( $35 \mathrm{~cm}$ de solo são capazes de atenuar cerca de 95\% da emissão gama),

- vegetação densa (a vegetação é capaz de absorver esses elementos atenuando as medidas de urânio e tório e diminuindo em até $15 \%$ as de potássio),
- umidade do solo (a presença de água fresca não-radioativa pode diminuir as medições para quase zero - Fig. 2),

- variações de temperatura atmosférica (que influencia a densidade do ar),

- umidade relativa e presença de nuvens

- fenômeno de inversão térmica, que pode impedir a dissipação do radônio livre na atmosfera gerando falseamento dos dados (Fig. 3),

- grande variação topográfica,

- efeitos direcionais (quando a janela do detector não está paralela ao plano de medida - Gunn 1998).

Além dos fatores citados, os dados gamaespectrométricos são diretamente afetados pelas características do levantamento efetuado como: distância entre o sensor e a superfície amostrada (altura de voo em levantamentos aéreos), espaçamento estre as linhas de aquisição e entre os pontos de medida etc. Mais a frente é apresentada uma breve descrição das principais características do aerolevantamento assim como do arranjo dos equipamentos utilizados.

O trabalho expõe didaticamente como utilizar o método da gama-espectrometria, especialmente em dados aerolevantados; abordam-se os equipamentos e configurações para o levantamento, técnicas de processamento e análise e procedimentos para interpretação final dos resultados, com apoio em exempos de casos reais de interesse geológico e econômico. O enfoque didático busca apresentar e divulgar o método gama espectrométrico como ferramenta robusta para mapeamentos geológicos de diversos objetivos, ressaltando vantagens, limi-

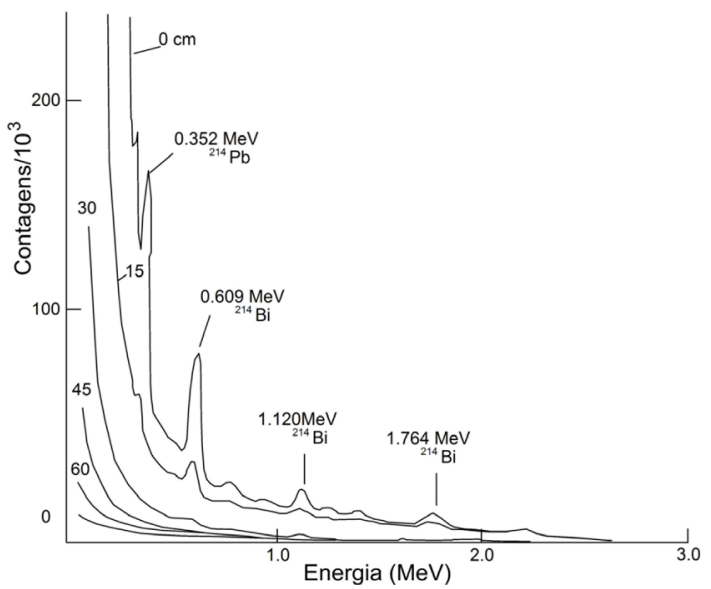

Figura 2. Variação da contagem dos elementos radiométricos em função do aumento da cobertura de água $(0,15,30,45$ e $60 \mathrm{~cm})$. Espectro do minério de urânio reproduzido de Dickson et al. (1979) 

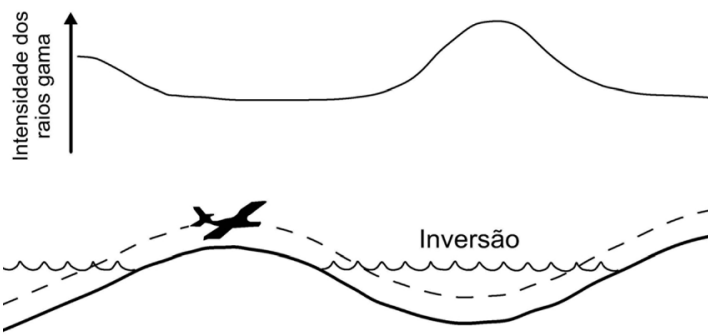

Figura 3. Variação nas contagens radiométricas associada à inversão térmica da atmosfera. (Modif. Hansen1980)

tações e, acima de tudo, valorizando uma utilização correta e eficiente.

\section{2 - Aerolevantamento e equipamentos}

Durante um aerolevantamento são sobrevoadas não apenas as linhas de medição, mas também linhas perpendiculares a essas com maior espaçamento, denominadas "Ties" (amarras) que constituem as linhas de controle (Fig. 4).

A concentração de radônio livre na atmosfera não é homogênea e pode representar um aumento de até $50 \%$ nas contagens associadas ao canal de urânio. Para a retirada dessa influência é utilizada a configuração downward/upward-looking dos detectores radiométricos descrita em seguida.

Grasty et al. (1988) descrevem a configuração utilizada pelo Geological Survey of Canada para os detectores e a blindagem de chumbo durante os aerolevantamentos realizados (Fig. 5). A configuração consiste em três caixas isoladas termicamente cada uma delas contendo quatro cristais de iodeto de sódio. Os detectores (upward looking), também contidos em uma caixa termicamente isolada, foram postos sobre os demais detectores (downward looking) e isolados verticalmente por uma folha de chumbo.

Segundo Nielson et al. (1990), as energias

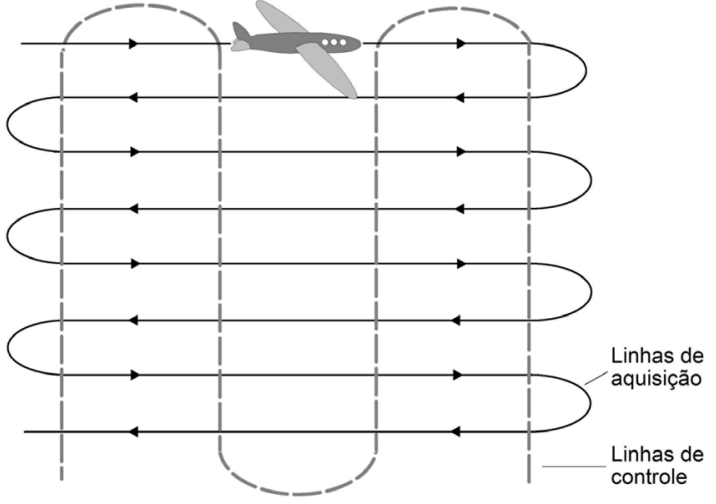

Figura 4. Esquema de um aerolevantamento

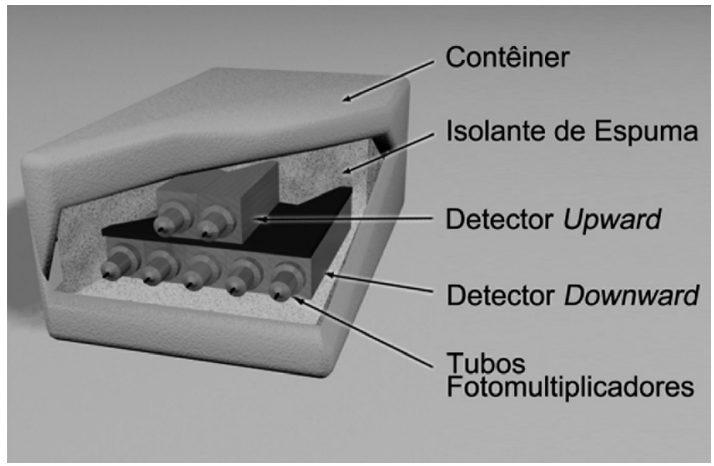

Figura 5. Diagrama da configuração dos detectores downward e upward-looking (Modif. Grasty et al. 1988)

monitoradas pelos sensores downward geralmente estão contidas nas janelas entre 1.37-1.57 (potássio), 1.66-1.86 (urânio), 2.41-2.81 (tório) e 0.41-2.81 $\mathrm{MeV}$ (contagem total). Os detectores upward, por sua vez, medem apenas a energia contida na janela de 1.66-1.86 MeV, selecionada para monitorar a radiação gama gerada pelo ${ }^{213} \mathrm{Bi}$ produzido pelo decaimento do radônio atmosférico.

Antes da interpretação dos dados amostrados, é necessário fazer a correção destes em função da radiação de fundo da aeronave, da altura efetiva de voo, radiação cósmica, etc. As correções são muito importantes para evitar possíveis falseamentos dos dados (como contagens erroneamente mais elevadas de um ou mais elementos), o que pode levar a geração de anomalias irreais e, por conseguinte, a uma interpretação errônea dos dados. Abaixo é apresentada uma descrição das correções a serem feitas nos dados radiométricos.

\section{3 - Processamento dos dados}

As correções dos dados gamaespectrométricos obtidos tanto a partir de um levantamento terrestre quanto aéreo devem seguir as recomendações especificadas nos relatórios técnicos desenvolvidos pela Agência Internacional de Energia Atômica (IAEA 1991 e 2003). Para tal é considerada a correção de "tempo morto", o cálculo da altura efetiva de voo, espalhamento Compton, radiação de fundo (background - BKG) e correção altimétrica. Ao contrário dos aerolevantamentos de magnetometria em que o magnetômetro está localizado na parte externa da aeronave (string), os dados de gamaespectrometria não apresentam efeito de paralaxe uma vez que os gamaespectrômetros estão no interior do avião e, portanto, próximos ao altímetro, não sendo neces- 
sária a correção.

Uma descrição mais detalhada das correções é apresentada abaixo.

\section{1 - Correções do Processamento}

\subsection{1 - Tempo morto}

O tempo em que o gama-espectrômetro grava as contagens medidas é denominado "tempo morto” (dead time), uma vez que nesse período não são registradas novas contagens. A correção dessa defasagem é feita pela divisão das contagens registradas nos canais pelo valor do "live time" (tempo total de medida) registrado pelo aparelho normalizando, assim, os valores brutos de contagens por segundo nos vários canais (contagem total, potássio, urânio, tório e urânio upward). Um valor típico para o tempo morto é da ordem de 5-15 $\mu \mathrm{s} /$ pulso, e pode ser corrigido pela fórmula (IAEA 2003):

$$
N=\frac{n}{1-C_{T} \cdot t}
$$

onde $N$ representa o valor corrigido de contagem em contagens por segundo (cps), $n$ é o valor das contagens observadas em cps, $C_{T}$ é a contagem total de todos os canais e $t$ é o valor do "tempo morto" do equipamento por pulso.

É importante ressaltar que, para os equipamentos mais modernos, a defasagem pode ser considerada desprezível.

\subsection{2 - Cálculo da Altura Efetiva (He) do Voo}

A altura de voo não se mantém constante ao longo de todo levantamento principalmente devido a irregularidades na topografia (Fig. 6). Sendo assim, é necessário fazer a correção dessa variação. $\mathrm{O}$ ajuste é feito com base na temperatura e pressão ambientais a partir da fórmula (IAEA 2003):

$$
H e=h \cdot\left(\begin{array}{c}
273,15 \\
T
\end{array}+273,15\right) \cdot\left(\begin{array}{c}
P \\
1013,25
\end{array}\right)
$$

onde:

$h$ - altura de voo medida pelo radar altímetro (em metros),

$T$ - temperatura do ar medida $\left(\mathrm{em}^{\circ} \mathrm{C}\right)$,

$P$ - pressão atmosférica (em milibar).

A pressão atmosférica é obtida da altitude medi-

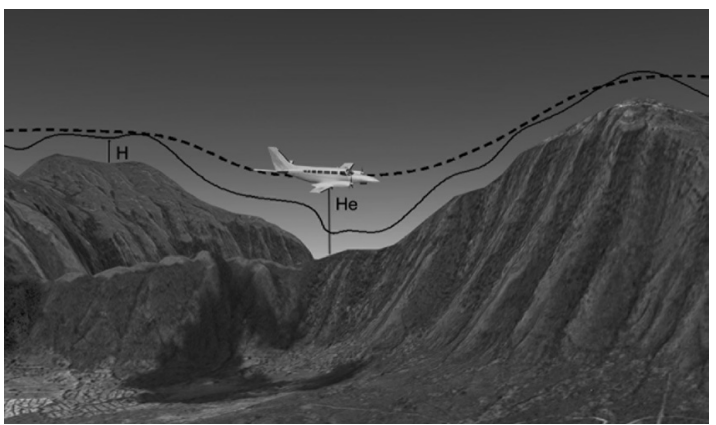

Figura 6. Esquema da variação entre altura nominal (pontilhado) e altura real (linha cheia) do avião ao longo de um aerolevantamento

da pelo altímetro barométrico.

\subsection{3 - Remoção do Background da Aeronave e Cósmico}

O background é calculado a partir da soma das contribuições da influência da aeronave e da radiação cósmica em cada uma das janelas do gama-espectrômetro. O cálculo dessas contribuições é feito através da equação (3) (IAEA 1991):

$$
N=a+b \cdot C
$$

onde:

$N$ - somatória das contribuições da aeronave e cósmica (em cps),

$a$ - background da aeronave em cada janela (em cps),

C - contagens observadas no canal de radiação cósmica (em cps),

$b$ - razão entre a contagem em uma determinada janela e a contagem no canal cósmico.

As estimativas dos valores associados aos coeficientes $a$ e $C$ são feitas durante o Voo Cósmico (Cosmic Flight), efetuado sobre uma grande superfície de água (ex: grandes lagos, mar, etc.) considerando altitudes diferentes (ex. 1.0, 1.5, 2.0, $2.5, \ldots, 3.5 \mathrm{~km})$.

\subsection{4 - Remoção do Background do Radônio Atmosférico (Uup)}

O efeito da radiação de fundo (background) associado ao radônio atmosférico é determinado a partir de medições feitas na janela do urânio pelo detector com configuração "upward looking". A expressão que define a contribuição do radônio nessa janela é dada por (IAEA 1991):

$$
U_{r}=\frac{u-a_{1} U-a_{2} T h+a_{2} b_{t}-b_{u}}{a_{u}-a_{1}-a_{2} a_{t}}
$$


onde:

$U_{r}$ - background do radônio observado no canal do urânio pelo detector downward;

$u$ - contagem medida no canal do urânio pelo detector upward;

$U$ - contagem medida no canal do urânio pelo detector downward;

Th - contagem medida no canal do tório pelo detector downward;

$a_{1}, a_{2}, a_{u}, a_{t}, b_{u}, b_{t}$ - coeficientes de proporcionalidade derivados da calibração adequada.

A descrição completa da calibração necessária para o detector upward looking pode ser encontrada em IAEA (1991).

A relação entre as contagens associadas ao radônio atmosférico, observadas tanto na janela do urânio, como nas demais janelas dos sensores downward, podem ser determinadas através da regressão linear. Segundo a IAEA (1991), os coeficientes que expressam a relação entre as medidas dos detectores downward e upward são calculados por:

$$
\begin{aligned}
& u_{r}=a_{u} U_{r}+b_{u} \\
& K_{r}=a_{k} U_{r}+b_{k} \\
& T_{r}=a_{t} U_{r}+b_{t} \\
& T C_{r}=a_{t c} U_{r}+b_{t c}
\end{aligned}
$$

onde:

$u_{r}$ é a componente do radônio no urânio $u p ; \mathrm{e} U_{r}$, $K_{r}, T_{r}$ e $T C_{r}$ são as contribuições do radônio nas janelas associadas aos detectores downward;

A regressão linear dos valores obtidos pela subtração do background da aeronave e cósmico das medidas obtidas no Voo Cósmico fornece os coeficientes de calibração $a_{u}, a_{k}, a_{t}, a_{t}, b_{u}, b_{k}, b_{t} \mathrm{e}$ $b_{k}$ (IAEA 2003).

Se os componentes dos backgrounds associados à aeronave e cósmico forem perfeitamente removidos, as constantes $b_{r}, b_{k}, b_{t}$ e $b_{t c}$ podem ser zeradas (IAEA 1991).

O segundo estágio da calibração consiste em relacionar as taxas de contagens medidas na janela do urânio upward às observadas na janela do urânio downward associado à presença desse elemento no solo. A relação é dada por (IAEA 2003):

$$
u_{g}=a_{1} U_{g}+a_{2} T_{g}
$$

onde:

$u_{g}, U_{g}$ e $T_{g}$ são as componentes associadas ao solo, $a_{1}$ e $a_{2}$ são os coeficientes de calibração neces- sários dessa equação. Segundo a IAEA (2003), o meio mais fácil de determinar os coeficientes $a_{1}$ e $a_{2}$ é a partir do dado corrigido do background adquirido através de voos/aquisições sobre regiões de grandes corpos de água. Os perfis obtidos por essas linhas são utilizadas para remover o background total e obter uma estimativa de $u_{g}, U_{g}$ e $T_{g}$. Segundo IAEA (1991), os coeficientes $\boldsymbol{a}_{1}$ e $\boldsymbol{a}_{2}$ podem ser estimados a partir da resolução do sistema:

$$
\begin{gathered}
a_{1} \sum\left(U_{g}\right)^{2}+a_{2} \sum U_{g} T_{g}=\sum u_{g} U_{g} \\
a_{1} \sum U_{g} T_{g}+\underset{(10),}{a_{2} \sum_{(1),}}\left(T_{g}\right)^{2}=\sum u_{g} T_{g}
\end{gathered}
$$

\subsection{5 - Correção do Efeito Compton}

A Correção do Efeito Compton é aplicada para eliminar a influência das radiações atribuídas aos canais de mais alta energia nos canais de menor energia. Ou seja, contribuições do tório observadas nos canais de potássio e urânio e contribuições do urânio no canal de potássio.

Nos sistemas atuais de levantamento, de maior resolução, são consideradas também as influências de radiações de baixa energia nas janelas de energia mais alta, resultando assim em seis coeficientes considerados para a correção:

$$
\begin{aligned}
& \alpha \text { - radiações de tório no urânio, } \\
& \beta \text { - radiações de tório no potássio, } \\
& \gamma \text { - radiações de urânio no potássio, } \\
& \text { a - radiações de urânio no tório, } \\
& \text { b - radiações de potássio no tório, } \\
& \text { g - radiações de potássio no urânio. }
\end{aligned}
$$

\subsection{6 - Correção Altimétrica}

Para eliminar falsas anomalias geradas por elevações na topografia, os valores radiométricos são referidos à altura nominal do aerolevantamento (Fig. 6).

A atenuação das radiações gama em relação ao afastamento da fonte pode ser expressa pela fórmula (IAEA 1991):

$$
N_{H}=N_{0} \cdot e^{-\mu \cdot H}
$$


onde:

$N_{H}$ - a radiação á distância $H$ da fonte,

$N_{0}$ - a radiação na superfície do terreno, ou seja, $H=0$,

$\mu$ - coeficiente da atenuação atmosférica.

Calculando-se o logaritmo da equação acima, tem-se uma equação da reta com coeficiente angular $-\mu$ e coeficiente linear $h\left(N_{0}\right)$, dada por:

$$
\operatorname{Ln}\left(N_{H}\right)=-\mu . H+\operatorname{Ln}\left(N_{0}\right)
$$

\subsection{7 - Conversão para Concentração dos Elementos}

Para determinar a sensibilidade dos detectores em relação às janelas dos elementos radiométricos é considerada a razão entre as medições efetuadas tanto a bordo $(\mathrm{N})$ quanto em terra $(\mathrm{C})$, ou seja:

$$
S=\frac{N}{C}
$$

onde:

$\mathrm{S}$ - sensibilidade para cada janela,

$\mathrm{N}$ - média das contagens corrigidas (em cps) para cada canal referente à altura nominal do levantamento e situada no trecho de interesse das estações terrestres utilizadas,

C - média das concentrações para cada canal das estações terrestres de interesse.

Para calcular a "taxa de exposição" E (Exposure Rate) do canal de contagem total (em $\mu \mathrm{R} / \mathrm{h})$, utiliza-se a fórmula abaixo (IAEA 1991):

$$
E=1,505 . K+0,0653 . e U+0,287, e T h
$$
onde:

$\mathrm{K}$, eU e eTh correspondem às concentrações aparentes destes elementos definidas em terra.

\section{4 - Caracterização dos elementos}

A interpretação dos dados gamaespectrométricos pode muitas vezes adicionar informações importantes sobre a composição das unidades litológicas de uma determinada região, assim como sobre a localização de regiões com maior ou menor concentração de um elemento, o que pode ajudar a delimitar áreas de interesse para exploração. Porém, como a gamaespectrometria tem pouco alcance em profundidade, as informações obtidas para interpre- tação limitam-se a contatos geológicos superficiais e/ou afloramentos de uma formação.

Para interpretar os mapas das concentrações de K, Th, U, CT e Ternário devem ser consideradas as características geoquímicas, a cristalografia, a abundância de cada elemento e suas principais ocorrências. Abaixo segue uma descrição sobre as principais características dos elementos radiométricos (potássio, tório e urânio) na natureza.

\section{1 - Potássio (K)}

O potássio aparece com abundância média de $1,50 \%\left(1,81 \% \mathrm{~K}_{2} \mathrm{O}\right)$ ao longo da crosta continental, concentrando-se em maior quantidade na parte superior $\left(2,32 \% \mathrm{~K}, 2,80 \% \mathrm{~K}_{2} \mathrm{O}\right)$ do que na inferior $\left(0,51 \% \mathrm{~K}, 0,61 \% \mathrm{~K}_{2} \mathrm{O}\right.$; Rudnick \& Gao 2004 , Ulbrich et al. 2009).

A principal ocorrência do potássio em associações minerais se dá nos feldspatos potássicos. Seus polimorfos mais abundantes são o ortoclásio e o microclínio, com teores desse elemento variando de $2,45 \%$ a $13,28 \%$ (Cox et al. 1979). O elemento ocorre também em micas, como flogopita $(8,13 \%$ de $\mathrm{K})$, biotita $(6,64 \%$ a $7,76 \%$ de $\mathrm{K})$, e muscovita $(8,30 \%$ a $9,30 \% \mathrm{~K})$, e em alguns argilominerais formados durante a diagênese ou por alteração hidrotermal.

Não são observadas ocorrências de potássio entre os minerais mais abundantes da crosta continental, como quartzo, olivinas, cloritas e carbonatos, sendo este observado apenas em teores muito baixos nos piroxênios ou anfibólios mais comuns (Dickson \& Scott 1997).

As rochas que apresentam maior teor de potássio são as rochas ígneas félsicas, como granitóides e sienitóides, assim como seus equivalentes vulcânicos, e rochas metamórficas micáceas, feldspáticas e quartzo-feldspáticas, como filitos, xistos e gnaisses. O elemento é também constituinte importante de rochas sedimentares, como folhelhos e argilitos.

O teor registrado de potássio nas demais rochas sedimentares, assim como em rochas ígneas intermediárias e basálticas (e seus equivalentes metamórficos como os anfibolitos), varia de baixo a moderado. Para rochas ultramáficas e seus equivalentes metamórficos, por sua vez, o teor é considerado muito baixo.

O potássio apresenta alta mobilidade durante $\mathrm{o}$ intemperismo e em ambientes de alteração hidrotermal, principalmente ambientes de clima tropical a subtropical (Wilford et al. 1997). Uma vez que 
o potássio é lixiviado dos minerais primários, ele pode ser facilmente absorvido por argilominerais como ilita, montmorilonita e, em menor proporção, caulinitas.

\section{2 - Tório (Th) e Urânio (U)}

$\mathrm{Na}$ crosta continental, o urânio apresenta um valor médio de $1,3 \mathrm{ppm}$, sendo sua concentração maior na parte superior da crosta $(2,7 \mathrm{ppm})$ do que na inferior $(0,2 \mathrm{ppm})$. O tório, por sua vez, apresenta valor médio de 5,6 ppm ao longo da crosta continental, podendo atingir teor de até $10,5 \mathrm{ppm}$ na parte superior enquanto que na parte inferior, bem mais exaurida, a concentração de tório é de aproximadamente 1,2 ppm (Rudnick \& Gao 2004).

Tanto o tório quanto o urânio estão comumente presentes em minerais acessórios, de variadas rochas ígneas e metamórficas quartzo-feldspáticas (Boyle 1982).

Como esses elementos são menos móveis do que o potássio, uma vez retirados das suas respectivas rochas fontes durante o intemperismo, eles são facilmente absorvidos por argilominerais e co-precipitados com óxidos de ferro nos solos, tendendo assim a se concentrar em ambientes mais desenvolvidos do que o potássio (Wilford et al. 1997).

Segundo Silva (2006), o urânio pode formar minerais solúveis, diminuindo assim a concentração deste. Entretanto, minerais insolúveis desse elemento tendem a não migrar, exceto no caso de serem transportados. Os minérios de urânio estão rochas com concentrações anômalas de ambos os elementos, como é o caso de depósitos do tipo aluvionar ou litorâneos (Vasconcellos 1994).

O urânio pode acompanhar o potássio ao longo dos processos hidrotermais ao contrário do tório, o qual apresenta a menor mobilidade geoquímica dos três elementos. O fenômeno é conhecido como antagonismo de Ostrovsky (1975) entre tório e potássio.

Segundo Dickson \& Scott (1997), a maioria dos minerais com alto teor de Th, como a monazita e o zircão, é estável durante o intemperismo e pode se acumular em depósitos de areia contendo minerais pesados. O tório livre, devido à quebra do mineral durante o intemperismo, pode ser retido nos óxidos-hidróxidos de $\mathrm{Fe}$ e $\mathrm{Ti}$ ou mesmo em argilitos. Assim como o urânio, o tório também pode se fixar em argilas coloidais e óxidos de ferro.

Estudos desenvolvidos por esses autores sobre teor médio dos radioelementos nas rochas ígneas mostrou que há uma tendência de aumento da quantidade destes em função do teor de sílica, ou seja, rochas félsicas possuem um teor mais elevado de radioelementos do que rochas máficas ou ultrabásicas (Fig. 7). Segundo os autores, o tório geralmente apresenta um crescimento maior do número de contagens em função do teor de sílica comparativamente ao urânio, o que torna possível utilizar a razão entre esses elementos $(\mathrm{Th} / \mathrm{U})$ para investigar o grau de diferenciação dentro de uma suíte ígnea. As rochas formadas no último estágio de colocação ígnea (ex: pegmatitos), durante a redução das temperaturas, apresentam altos teores de presentes em pegmatitos, sienitos, carbonatitos, granitos, gnaisses e alguns folhelhos (Gunn et al. 1997).

A solubilidade dos complexos de tório geralmente é baixa, exceto em caso de soluções ácidas (Langmuir \& Herman 1980). O tório pode estar presente nos seguintes minerais: alanita, monazita, xenotima e zircão em níveis superiores a $1000 \mathrm{ppm}$ ou como vestígios em outros minerais formadores de rochas (Dickson \& Scott 1997).

Nos sedimentos arenosos, o teor de urânio geralmente é menor que 1 ppm devido à facilidade de lixiviação desse elemento. Porém, quando os sedimentos são originados a partir da erosão de rochas ígneas com minerais resistentes de tório e urânio, estes podem formar

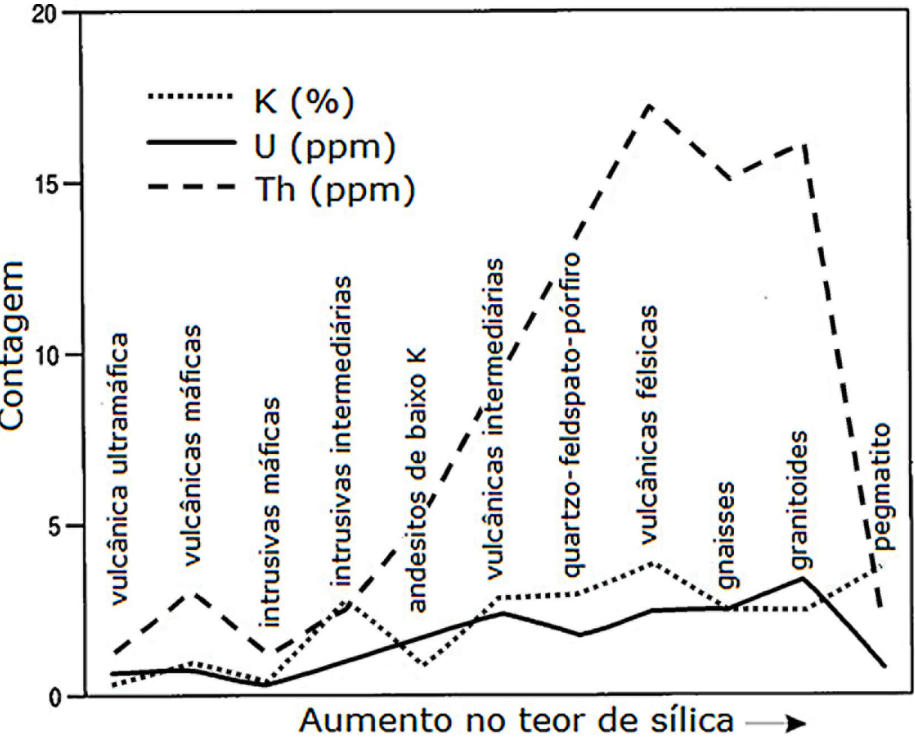

Figura 7. Variação nos teores médios de Th e U nas rochas ígneas em relação ao teor de sílica (Si) (Modif. de Dickson \& Scott 1997) 
Tabela 2. Variação da concentração média dos radioelementos em rochas e solos na Austrália (Modif. de Dickson \& Scott 1997)

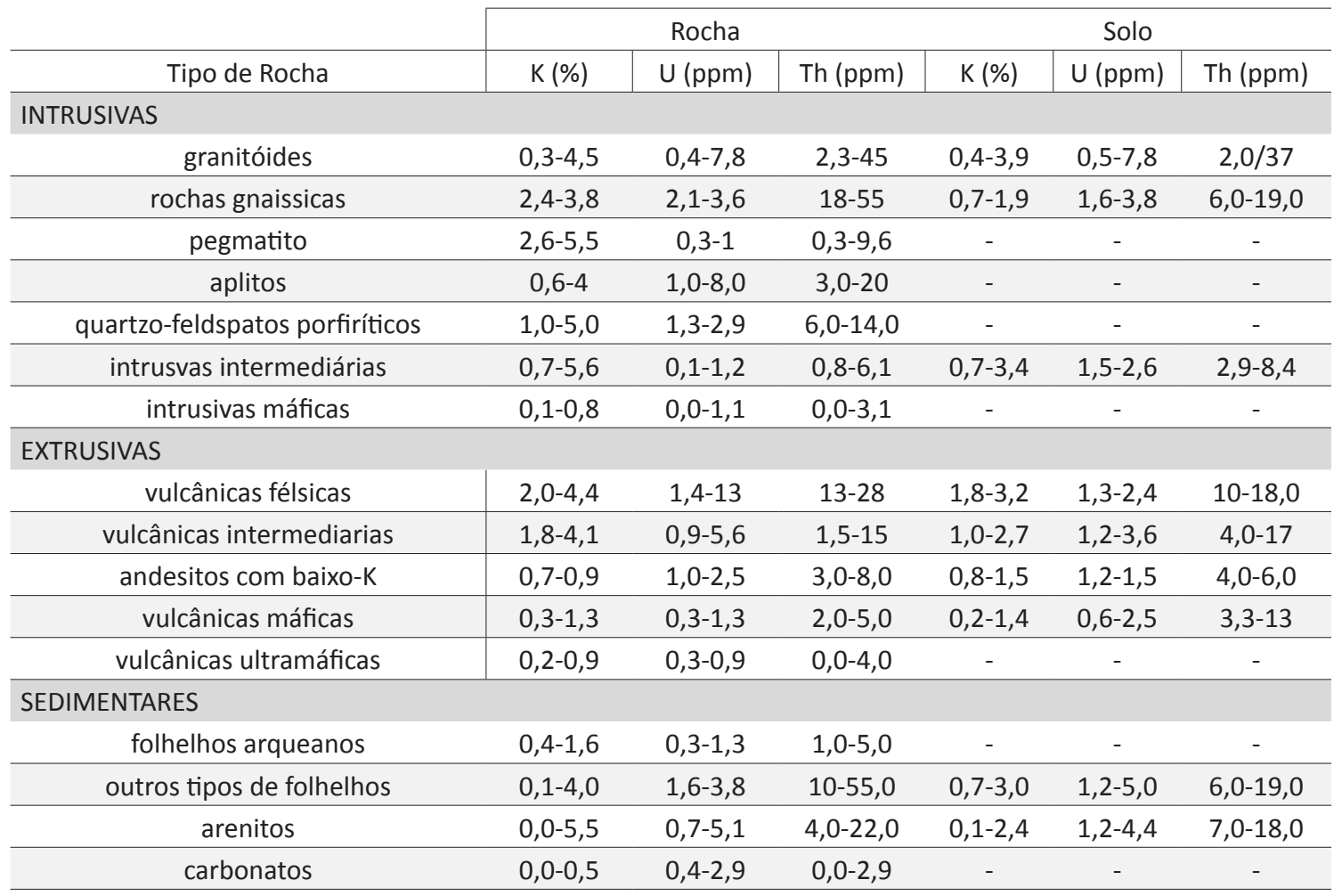

potássio e quantidades menores de tório e urânio, entretanto, rochas tardias ocupam áreas pequenas e muitas vezes não apresentam influência no aerolevantamento.

A Tabela 2 mostra a variação da concentração média dos radioelementos em rochas e solos na Austrália (Dickson \& Scott 1997).

Segundo Wilford et al. (1997), o equilíbrio observado na denudação da paisagem, ou das taxas relativas à formação de regolito (manto de alteração) versus as taxas de erosão, pode ser estudado através dos dados radiométricos. A resposta gamaespectrométrica de uma área com forte erosão (por exemplo, regiões de declive ou escarpa - Fig. 8) reflete a composição mineralógica e geoquímica das camadas inferiores, pouco intemperizadas e possivelmente associadas ao pedólito (camada inferior do manto de alteração) ou ao embasamento; enquanto que regiões estáveis e/ou com deposição de sedimentos é provável que apresentem baixas contagens, resposta esperada para áreas de solo/ regolito.

\section{5 - Interpretação}

A radiação gama apresenta um maior índice de penetração tanto para fontes naturais quanto construídas pelo homem. Radio-nuclídeos individuais emitem raios gama com energia específica característica para cada elemento e isótopo, o que

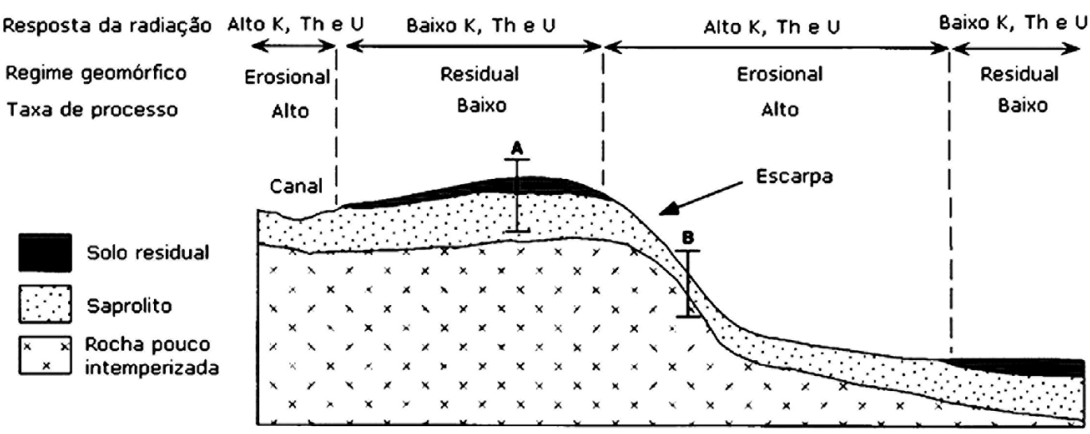

Figura 8. Influência dos processos geomorfológicos na emissão de radiação gama (Modif. de Wilford et al. 1997) torna a gamaespectrometria uma ferramenta extremamente útil para a caracterização de regiões com potencial exploratório ou com litologias indiferenciadas. Entre as principais aplicações da gamaespectrometria podemos citar:

- identificação de 
possíveis novos alvos exploratórios a partir da assinatura radiométrica de uma fonte conhecida (Cotis et al. 2013);

- estudo da assinatura radiométrica de intrusões ígneas aflorantes (Ribeiro et al. 2013),

- caracterização de intrusões classificadas como indiferenciadas pela geologia (Ulbrich et al. 2009),

- prospecção mineral (Fornazzari Neto e Ferreira 2003; Carrino et al. 2007),

- estudo de crateras de impacto (Vasconcelos et al. 2012),

- agricultura (ex. análise da influência de fertilizantes com derivados do urânio em rios e afluentes - Conceição e Bonotto 2003),

- exploração petrolífera (Saunders et al. 1987; Lüning e Kolonic 2003; IAEA 2003),

- controle ambiental em áreas com vazamento radioativo (IAEA 2003),

- auxiliar na determinação dos limites geológicos de grandes estruturas (Ribeiro e Mantovani 2012),

- caracterização de áreas com alteração hidrotermal (Biondi et al., 2001),

- entre outros.

A interpretação dos dados radiométricos pode levar em consideração diversos tipos diferentes de mapas, dependendo da informação a ser destacada/extraída dele. Para tal, é importante ter em mente as principais informações sobre a geologia e o contexto tectônico da região a ser estudada.

Os primeiros mapas gerados a partir dos dados gamaespectrométricos já corrigidos engloba a distribuição espacial das contagens de cada um dos elementos radiométricos (K, Th e $\mathrm{U}$ ) assim como a distribuição da Contagem Total (CT - referente à somatória de todas as contagens dentro da janela de energias $0,41-2,81 \mathrm{MeV}$ ).

\section{1 - Mapas Razões}

A partir das contagens individuais dos radioelementos é possível gerar os mapas de razões entre eles (U/Th, U/K e Th/K). Os mapas são utilizados para destacar a diferença observada entre as concentrações dos elementos radiométricos em corpos graníticos em uma mesma região ou mesmo identificação de áreas com forte alteração hidrotermal do tipo potássica e/ou sílica (dois tipos de alteração com maior concentração do elemento K).

Corpos graníticos diferenciados podem apresentar concentrações distintas dos elementos radiométricos $(\mathrm{K}$, Th e $\mathrm{U})$ visto que eles não apresentam comportamento geoquímico uniforme durante a granitogênese, embora para corpos de uma mesma região possam estar correlacionados. A variação de concentração é resultado principalmente da geologia local (predomínio de um ou outro tipo geoquímico de granitóide), do processo de enriquecimento (por exemplo, por diferenciação magmática e/ou por ação hidrotermal) e pelo grau de intemperismo sofrido. A diferença nos teores dos radioelementos fica evidente principalmente nos mapas de razão $\mathrm{U} / \mathrm{K}$ e Th/K, enquanto que o mapa de razão $\mathrm{U} / \mathrm{Th}$ apresenta contraste menos significativo.

A importância da identificação de áreas com alteração hidrotermal pela gamaespectrometria, por sua vez, se deve à possibilidade da relação deste processo com a ocorrência não apenas de metais base (cobre, chumbo e zinco) como de ouro e prata em diversos ambientes geológicos.

\section{2 - Fator $F$}

É possível também analisar a razão entre os elementos radiométricos a partir do cálculo do parâmetro F (Gnojek \& Prichystal 1985), o qual é definido por:

$$
F=K \times \frac{e U}{e T h}
$$

O mapa do parâmetro $\mathrm{F}$ realça o enriquecimento de potássio e urânio em relação ao tório, principalmente quando associado a áreas com alteração hidrotermal.

Áreas com forte intemperismo e alta lixiviação do potássio tendem a apresentar valores para o parâmetro $\mathrm{F}$ muito baixos, enquanto que maciços rochosos que foram submetidos ao enriquecimento de potássio e urânio por alteração hidrotermal tendem a apresentar altos valores.

\section{3 - Mapa Ternário}

O mapa ternário dos elementos radiométricos é gerado a partir da associação de uma determinada cor á cada um dos radioelementos dependendo do padrão de coloração utilizado (RGB ou CMY). O padrão RGB associa as cores vermelho, verde e azul (Red, Green, Blue) ao potássio (em \%), 


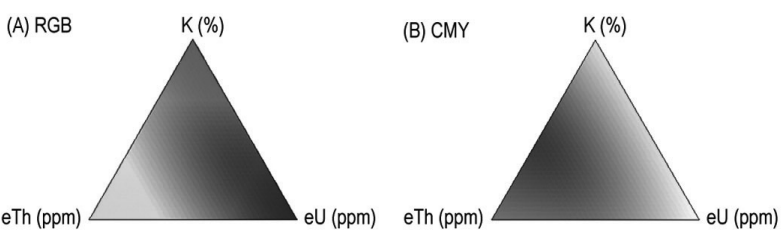

Figura 9. Exemplo de escala ternária para o sistema de cor (A) RGB e (B) CMY

tório e urânio (em ppm) respectivamente. O padrão CMY por sua vez considera as cores ciano, magenta e amarelo (Cyan, Magenta, Yellow) como base para composição do mapa. Em ambos os padrões, as cores são associadas a cada um dos vértices de um triangulo equilátero (Fig. 9), com gradações das cores variando de acordo com o teor de cada um dos elementos considerados, a cor branca representa altas contagens dos três elementos, enquanto que a cor preta é associada às baixas contagens dos mesmos.

Assim como os mapas de razões, o mapa ternário é utilizado para ressaltar contrastes entre áreas com diferentes concentrações dos três elementos que podem não estar tão evidentes nos primeiros mapas, facilitando assim a interpretação dos dados.

Nas figuras 10 e 11 estão dispostos os mapas das contagens de potássio, tório, urânio, contagem total, razões (U/Th, U/Ke Th/K) e mapas ternários (com padrão RGB e CMY) assim como o mapa do Fator $F$ definido na equação (16), interpolados para a região de Tapira, Minas Gerais. A interpretação desses mapas é apresentada por Ribeiro (2011).

\section{4 - Mapa de Interpretação “Litogeofísica”}

Para facilitar a interpretação do mapa ternário, e posterior comparação com o mapa geológico, pode ser gerado o mapa litogeofísico.

Esse mapa consiste principalmente na identificação de áreas com diferentes concentrações dos elementos radiométricos (potássio, tório e urânio) e discriminação destas a partir de uma legenda de cores.

\subsection{1 - Confecção de um mapa litogeofísico}

O mapa litogeofísico é um mapa de interpretação e tem como objetivo facilitar a visualização da distribuição dos três elementos radiométricos ao longo da área analisada. Para tal, ao contrário do mapa ternário no qual a legenda descreve a distribuição de cores a partir de um triangulo equilátero, na legenda do mapa litogeofísico o teor dos três
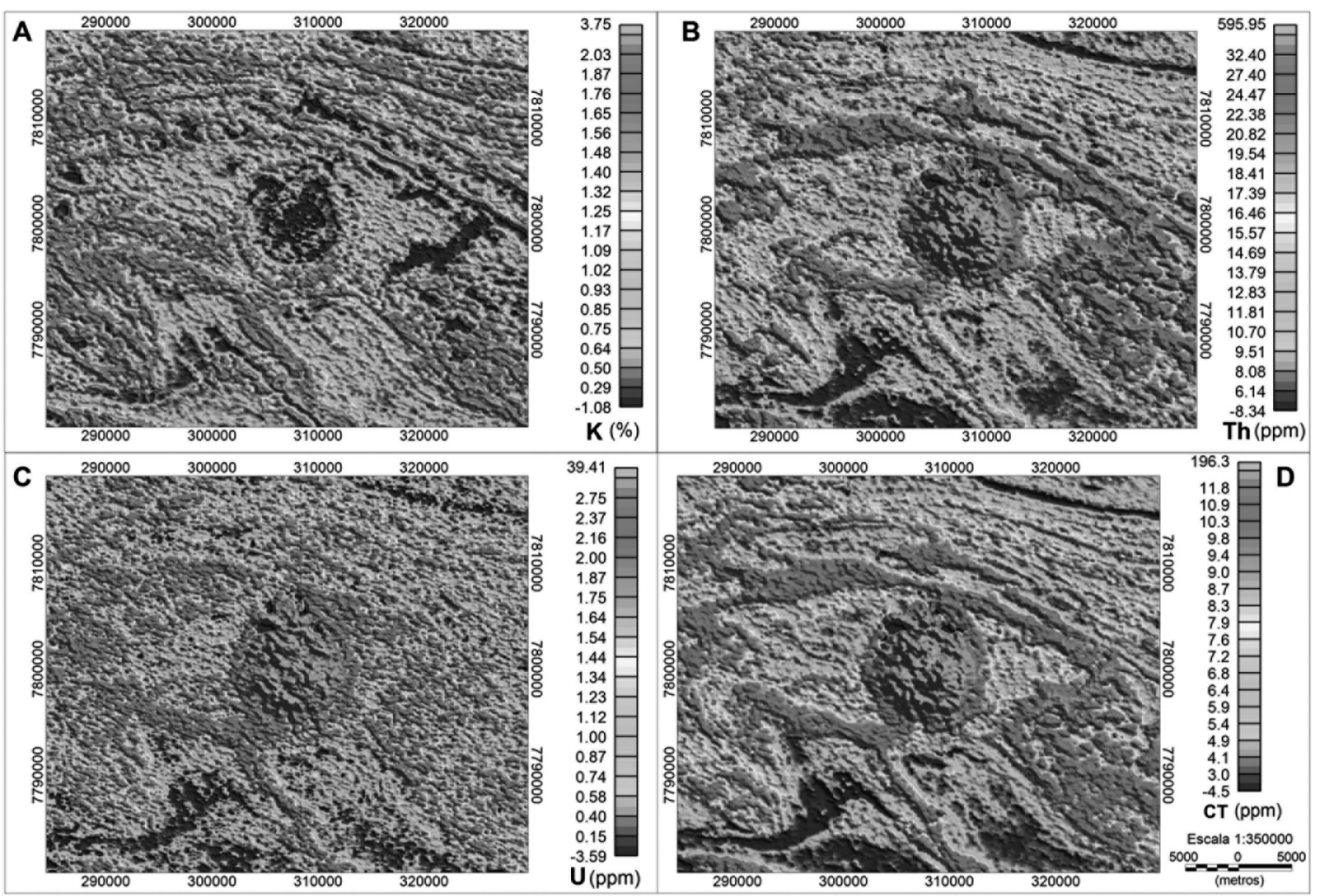

Figura 10. Mapa (A) das contagens de potássio, em \%; (B) das contagens de tório em ppm; (C) das contagens de urânio em ppm e (D) de contagem total. (Extraído de Ribeiro 2011) 


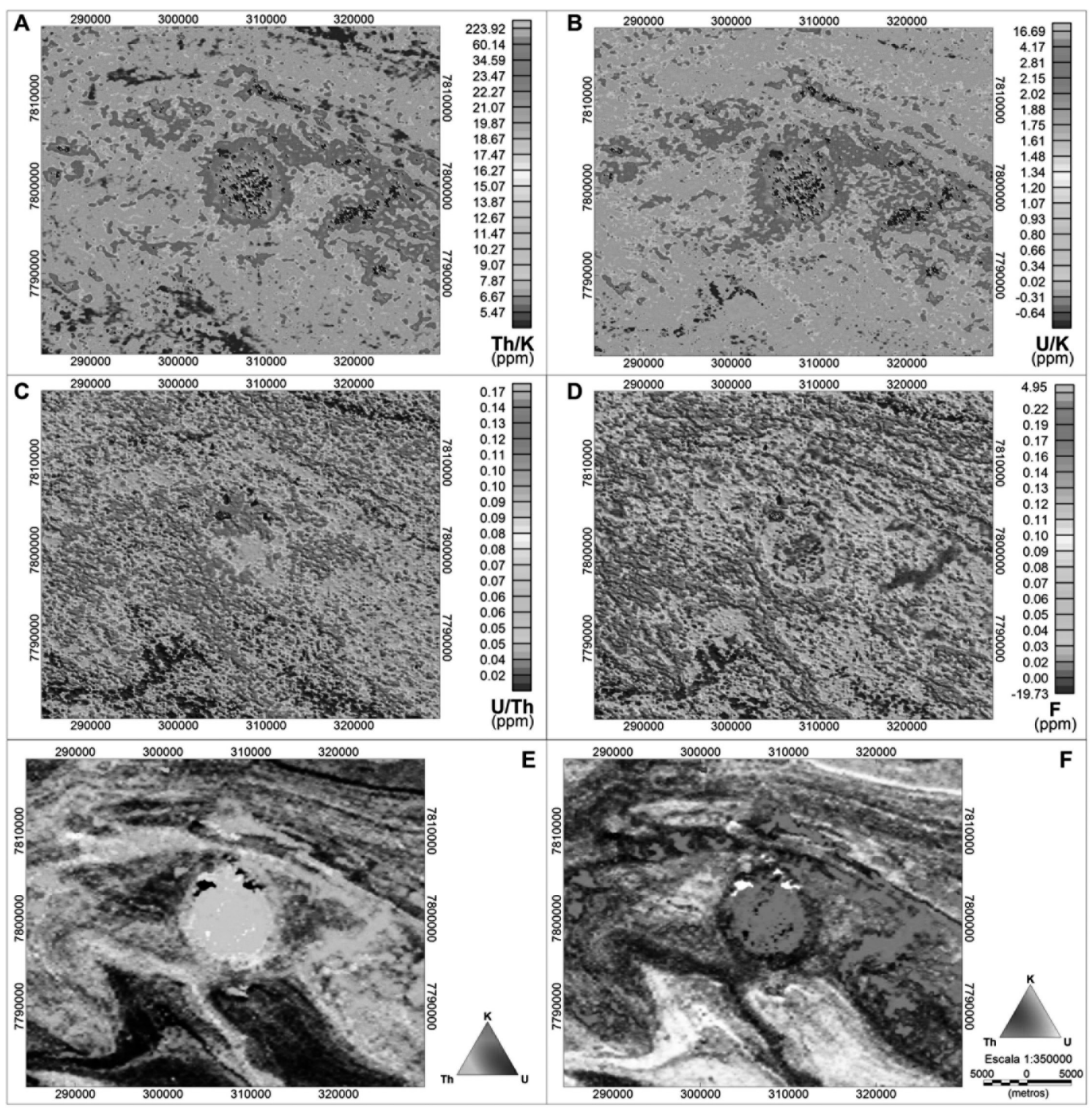

Figura 11. Mapa das razões (A) Th/K; (B) U/K; (C) U/Th em ppm; (D) mapa do fator $F(E)$ ternário com padrão RGB e (F) com padrão CMY (Extraído de Ribeiro 2011)

radioelementos já aparece associada a uma determinada cor discriminada.

Ao fazer um mapa litogeofísico é importante levar em consideração que quanto maior for o detalhamento empregado, maior será a chance de o mapa final apresentar falseamento principalmente entre contatos litológicos com composição parecida. Além disso, os mapas de contagens podem apresentar ruído ou áreas de baixa precisão, dependendo das condições do levantamento terrestre ou aéreo que podem prejudicar a confecção do mapa litogeofísico.

Porém o mapa não pode ser simplificado demais, pois pode retirar não apenas a influência do ruído no mapa, como também informações geológicas menos aparentes.

Sendo assim, antes da confecção do mapa litogeofísico propriamente dito, é necessário que sejam estabelecidos os limites das concentrações radiométricas que serão consideradas e as cores associadas a cada uma delas.

Um bom ponto de partida para definir o grau de precisão a ser empregado no mapa litogeofísico é observar a variação de concentração dos elementos ao longo das unidades litológicas observadas no mapa e, se for o caso, observar qual a precisão do mapa geológico da região para facilitar a comparação entre estes. 
Para exemplificar a confecção desse mapa, nas Figuras 16 e 17 são apresentados, respectivamente, o mapa com a distribuição ternária RGB dos radioelementos para a região do Batólito de Santa Helena e o mapa litogeofísico gerado a partir da interpretação deste. Estes mapas foram apresentados inicialmente no artigo intitulado "Contribuição Geofísica ao Estudo do Batólito Granítico de Santa Helena (MT)" (Ribeiro \& Mantovani 2012).

A seguir é apresentado um resumo da interpretação desses mapas fornecida pelas autoras, assim como a comparação destes com o mapa geológico e topográfico da região.

\section{6 - Estudos de caso}

Uma das principais aplicações do método da gamaespectrometria é a caracterização de diferentes rochas a partir do contraste dos teores de radioelementos entre elas. Apesar de o método apresentar resposta essencialmente superficial, este pode acrescentar informações importantes sobre uma região, as quais muitas vezes seriam invisíveis a olho nu.

A fim de exemplificar a utilização, abaixo é apresentada a análise da assinatura radiométrica observada para o Batólito de Santa Helena, localizado no Mato Grosso e para o Complexo Alcalino de Tapira, em Minas Gerais.

\section{1 - Batólito de Santa Helena (MT)}

\subsection{1 - Geologia}

Segundo Ruiz et al. (2004), o Batólito Santa Helena constitui uma intrusão de aproximadamente $3.500 \mathrm{~km}^{2}$, encaixada em rochas supra e infracrustais do Domínio Jauru. Os limites deste corpo, redefinidos por Ruiz et al. (2005), caracterizam-se pelo controle tectônico exercido pela Zonas de Cisalhamento Indiavaí-Lucialva (extremo NE), Piratininga e Estiva Velha (ocidental), enquanto que suas porções oriental e meridional são parcialmente recobertas por sedimentos carboníferos (Formação Jauru) e holocênicos (Formação Pantanal - Fig. 12).
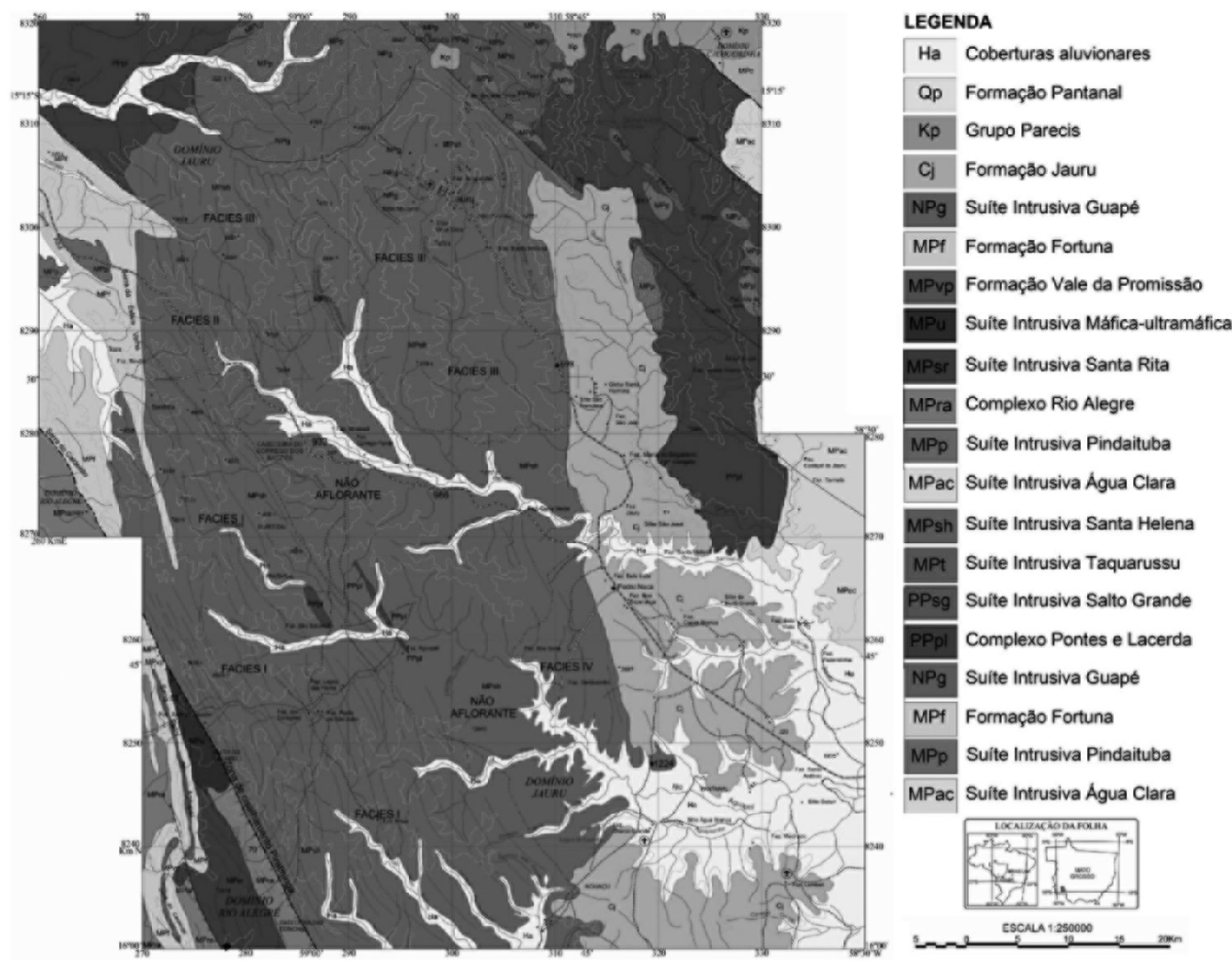

Figura 12. Mapa geológico da região onde se encontra o Batólito Santa Helena com a compartimentação em domínios estruturais proposta por Ruiz (2005) com base na orientação e natureza das estruturas tectônicas (foliações e lineações). Adaptado de Geraldes et al. (2001) 
Menezes et al. (1993, apud Ruiz 2005) caracterizam o batólito como tendo pequena diversidade composicional, sendo constituído por granitos de tendência alaskítica, foliados, cinza-avermelhados a róseos, apresentando resposta geoquímica com valores elevados de $\mathrm{Na}_{2} \mathrm{O}+\mathrm{K}_{2} \mathrm{O}$, baixos de $\mathrm{Al}_{2} \mathrm{O}_{3}$, muito baixo de $\mathrm{CaO}$ e enriquecimento nos valores de Elementos de Terras Raras (ETR), a qual os autores interpretaram como típica de granitos alcalinos do tipo A, enquanto que nas zonas marginais do batólito ocorre um enriquecimento em $\mathrm{Sr}, \mathrm{Ba}$ e Ti e um relativo empobrecimento de $\mathrm{Rb}$, Th, U, ETR e HFSE (elementos com alta valência como Sn e U, que não são facilmente incorporados ao retículo das rochas silícicas, sendo geralmente incorporados em fases acessórios durante a formação das rochas ígneas) em relação às partes centrais.

Geraldes et al. (2001), entretanto, caracterizam as rochas deste batólito como variando do granito tipo I para um granito mais fracionado com afinidades com o tipo A. Estes autores sugerem que o batólito foi formado durante a subducção orientada para leste subsequente à acresção das unidades do domínio Rio Alegre, e que a maior parte deste batólito foi derivada da recém agregada crosta Rio Alegre.

Geraldes (1996) destaca a presença de uma forte anomalia negativa de Európio $(\mathrm{Eu})$ na distribuição dos ETR nesse batólito, a qual este autor interpreta como um indicador de que este corpo foi formado a partir de um magma que sofreu diferenciação bimodal gerando assim uma suíte granítica e outra anortosítica. Nesta diferenciação, o plagioclásio cristalizado se concentra na suíte anortosítica, incorporando o $\mathrm{Eu}$, enquanto que a suíte granítica torna-se empobrecida neste elemento.

Segundo Geraldes et al. (2001), a zona central do Batólito Santa Helena é caracterizada por fácies de granulação grossa altamente deformada e intrudida por diques de granitóides com grãos médios muito menos deformados. A zona marginal deste batólito mostra graus variáveis de deformação, sendo as rochas localmente milonitizadas. Segundo os autores, o Batólito Santa Helena é composto principalmente por granitos com grande abundância de K-feldspatos (aproximadamente 40-50\% na porção central do batólito e $30-40 \%$ nas bordas), com apenas uma amostra classificada como granodiorito modal.

Com base em levantamentos de campo e nas análises petrográficas em lâminas delgadas, Ruiz (2005) propõe uma compartimentação do batólito em quatro fácies petrográficas preliminares (Fig. 12), as quais podem ser divididas em subfácies, à medida que se amplie o detalhamento geológico-petrográfico.

A fácies petrográfica I é composta principalmente por gnaisses mesocráticos a leucocráticos, de composição monzogranítica, com porfiroclastos de feldspato potássico. É relativamente comum a ocorrência neste setor de diques graníticos tabulares, com espessura variando de centímetros a alguns metros.

A fácies petrográfica II situa-se ao norte da fácies I e ao sul da fácies III, no entanto os limites entre as fácies não foram reconhecidos em campo por Ruiz (2005). Esta fácies é limitada a oeste pelo contato tectônico com o Grupo Aguapeí, através da Zona de Cisalhamento Estiva Velha. A composição mineralógica desta fácies difere da fácies I principalmente pela ausência do anfibólio e granada, e pela diminuta proporção de biotita (em torno de 5 a 10\%; Ruiz 2005).

A fácies petrográfica III é composta principalmente por gnaisses leucocráticos a mesocráticos, de composição monzogranítica, sendo comum os porfiroclastos de feldspato potássico alcançarem até $4 \mathrm{~cm}$ de comprimento. Ruiz (2005) ressalta o desenvolvimento de dobras de foliação nessa fácies, o qual evidencia o caráter polifásico do batólito Santa Helena.

A fácies petrográfica IV, delimitada por Ruiz (2005), estende-se das imediações do Posto Neca até a região do Rio Aguapeí, entretanto Ruiz (2005) ressalta que não foi possível reconhecer os limites dessa fácies em campo. Segundo este autor nesta fácies observa-se o predomínio de gnaisses leucocráticos a mesocráticos, prevalecendo uma composição monzogranítica.

\subsection{2 - Resultados da Análise Gamaespectrométrica}

As figuras que seguem apresentam o mapa de modelo digital de terreno (MDT - Fig. 13), assim como os de contagens dos radioelementos (K, Th e U - Fig. 14), contagem total (CT - Fig. 15) e mapa da distribuição ternária dos radioelementos (Fig. 16).

A análise do mapa ternário (Fig. 16) mostra uma distribuição heterogênea dos radioelementos, contrastante com as unidades litológicas ao redor do Batólito Santa Helena, principalmente em relação às altas contagens de potássio, as quais condizem com o esperado pela grande abundância de K-fel- 

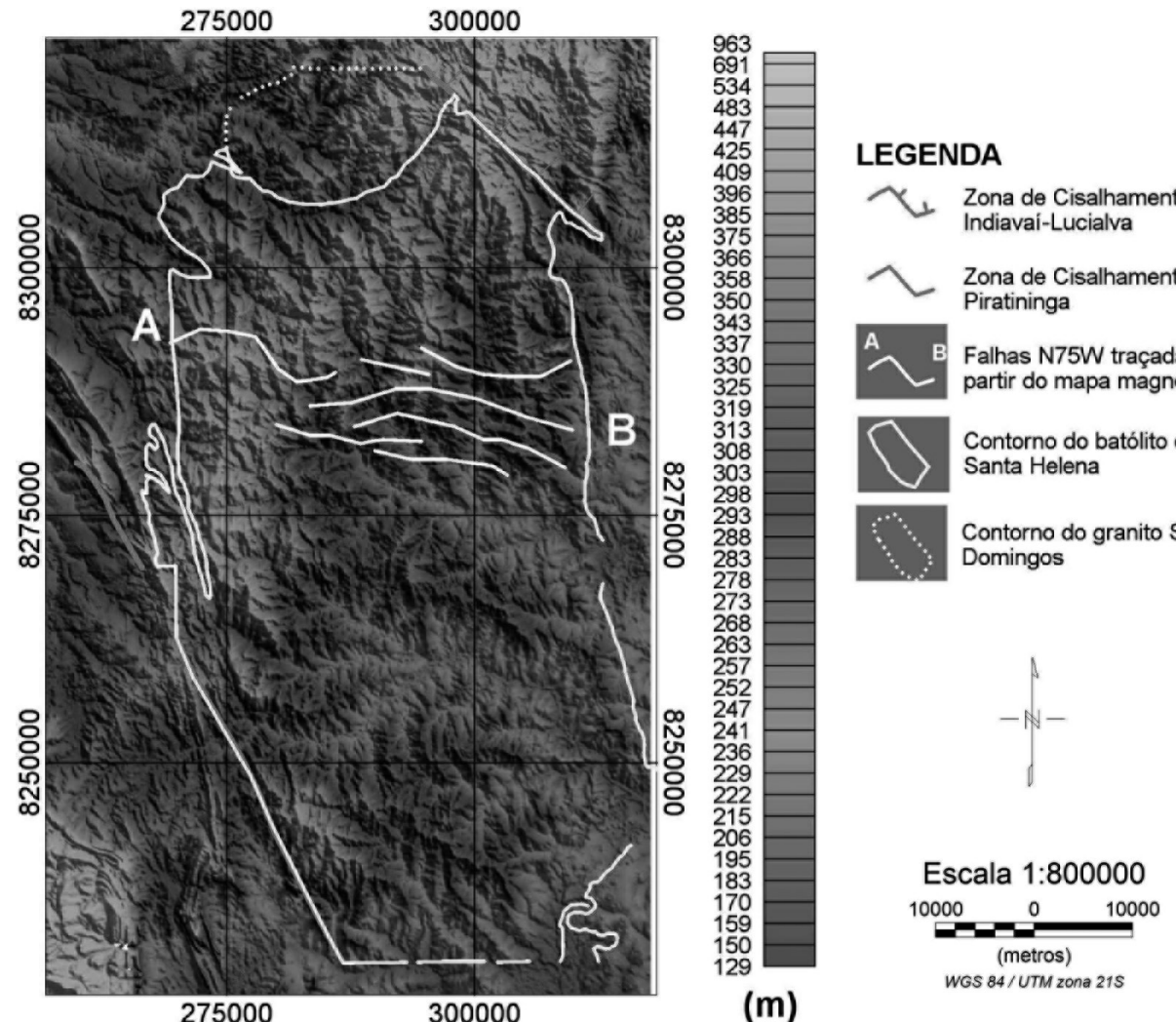

Figura 13. Mapa do modelo digital de terreno (MDT) obtido a partir dos dados do SRTM (Shuttle Radar Topography NASA) para a região de estudo. A linha continua $A B$ (em vermelho) indica a localização dos lineamentos magnéticos, enquanto que as linhas tracejadas e pontilhadas em branco correspondem, respectivamente, aos limites do Batólito Santa Helena e do granito São Domingos, definidos por Ruiz (2005)
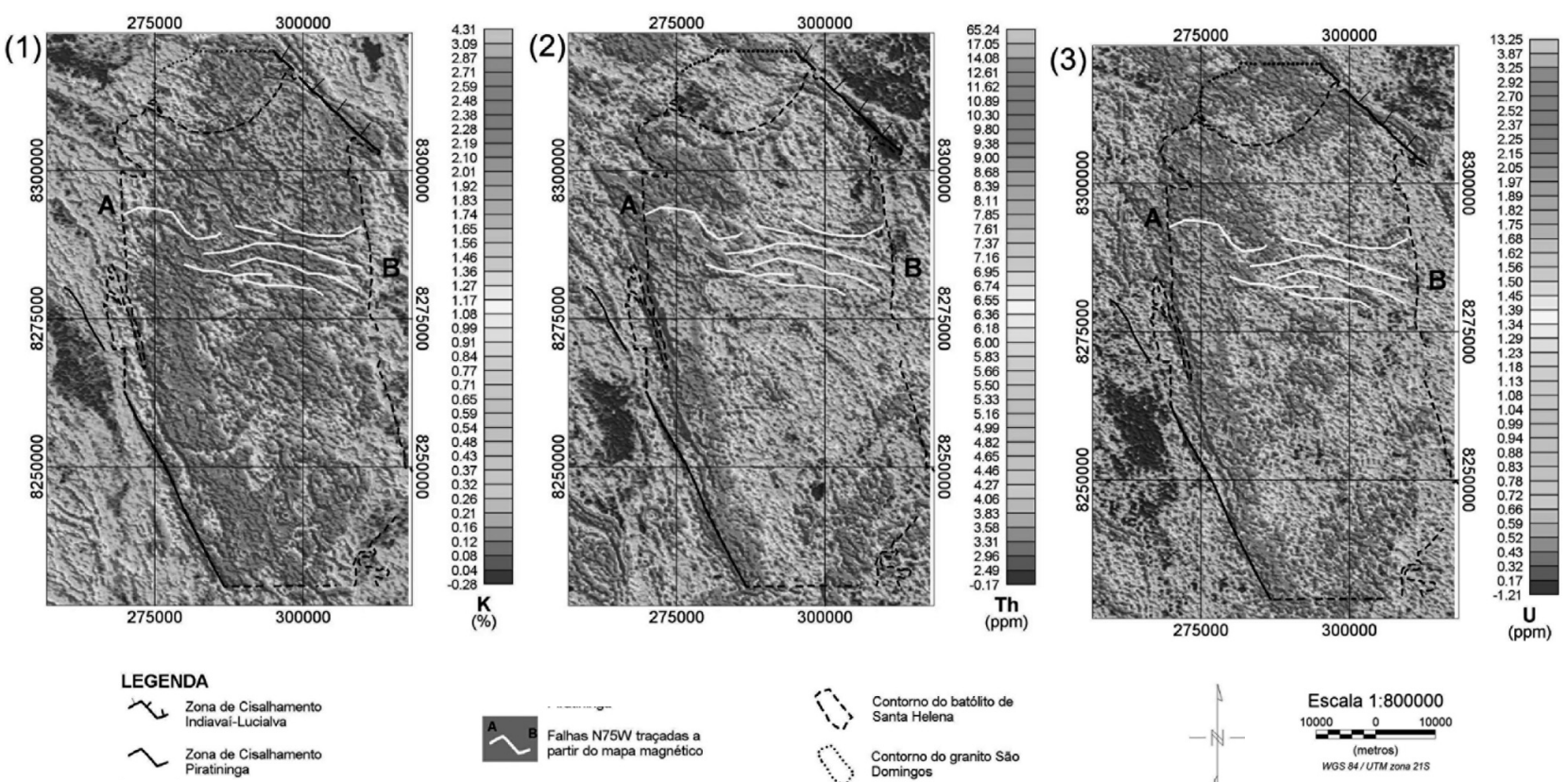

Figura 14. Mapa da distribuição das contagens de (1) potássio, (2) tório e (3) urânio observadas na região de estudo. As linhas brancas $A B$ indicam a localização dos lineamentos magnéticos, enquanto que as linhas tracejadas e pontilhadas em preto correspondem, respectivamente, aos limites do Batólito Santa Helena e do granito São Domingos, definidos por Ruiz (2005) 
dspatos observada por Geraldes et al. (2001). De fato, o mapa de contagem total (Fig. 15) evidencia o aumento dos teores dos radioelementos observados para o Batólito Santa Helena em detrimento das rochas circundantes.

O mapa ternário revela uma diferenciação na distribuição dos radioelementos ao longo das porções norte e sul, sendo estas separadas por um sistema de foliação identificado pelo perfil $\mathrm{AB}$ na Fig. 16. Esta diferenciação é ressaltada principalmente em relação aos mapas de contagem de potássio (Fig. 14-1).

A análise do mapa ternário permite identificar também uma grande diferença na distribuição dos radioelementos referente à porção oeste da intrusão, a qual apresenta um aumento expressivo nas contagens de tório e urânio se comparada ao restante do batólito. A diferenciação é observável não apenas nos mapas de contagem individual dos radioelementos (Fig. 14), mas também no mapa ternário (Fig. 16).

A porção setentrional do Batólito Santa Helena é caracterizada por apresentar contagens mais elevadas para o canal de potássio principalmente na região NE (Fig. 14-1). Ao contrário da porção meridional, este corpo apresenta uma faixa com altas contagens dos três elementos radioativos ao longo de toda sua borda, abrangendo um maior espaço no limite sudeste e na lateral oeste do corpo. Intrínsecas a este corpo são observadas duas regiões com coloração vermelho escuro no mapa ternário (identificadas pelos números $1 \mathrm{e}$ 2 na Fig. 16), as quais apresentam contagens medianas de potássio e baixas contagens de tório e urânio, também observadas nos mapas de contagens individuais desses elementos (Fig. 14). As duas anomalias radiométricas foram possivelmente
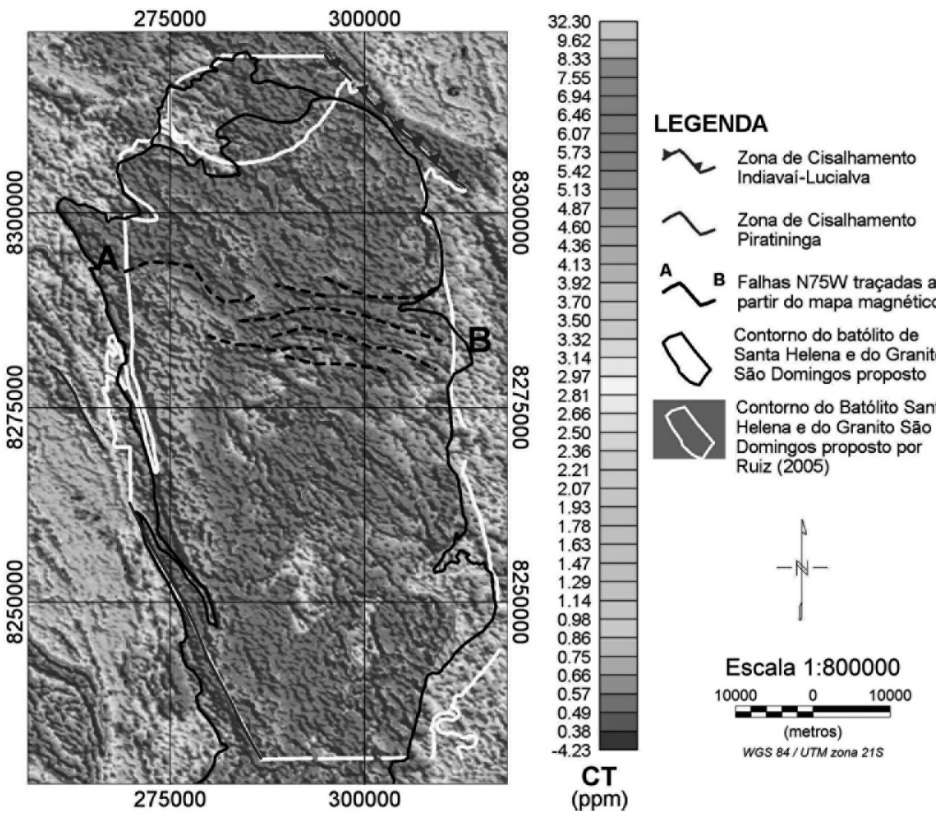

Figura 15. Mapa da contagem total de emissão dos radioelementos observado para a região do Batólito Santa Helena. As linhas contínuas, em preto e em branco representam, respectivamente, os contornos do batólito e do Granito São Domingos definidos a partir dos dados geofísicos e propostos por Ruiz (2005)

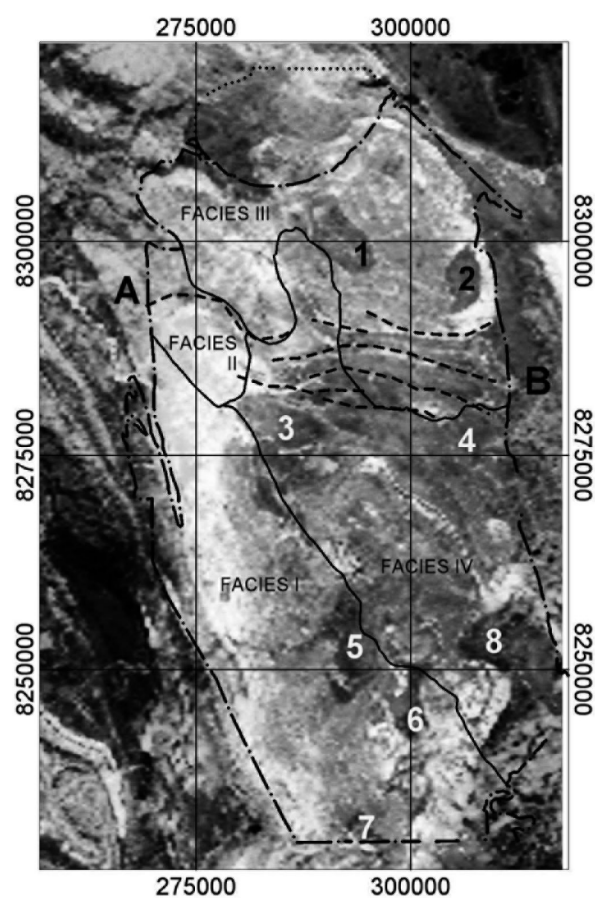

LEGENDA

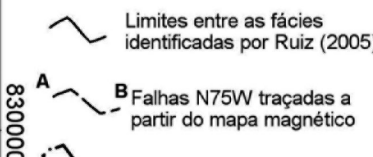

(1) Contorno do batólito de Santa Helena

Contorno do granito Săo Domingos

Anomalias com médias 1 - 8 a altas contagens de $K$ e baixas a médias de Th eU
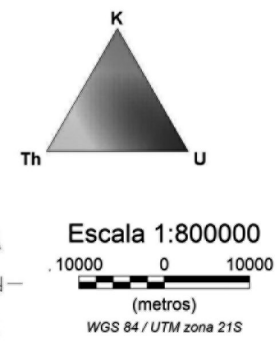

Figura 16. Mapa da distribuição ternária com padrão $\mathrm{RGB}=(\mathrm{K}, \mathrm{Th}, \mathrm{U})$ dos radioelementos na região de estudo. $A$ linha continua $A B$ indica a localização dos lineamentos magnéticos, enquanto que as linhas tracejadas e pontilhadas correspondem, respectivamente, aos limites do Batólito Santa Helena e o granito São Domingos definidos por Ruiz (2005). As anomalias radiométricas internas ao batólito estão numeradas de 1 a 7 
te Intrusiva Guapé (NPg - Fig. 12) e ao Complexo metavulcanosedimentar Pontes e Lacerda (PPpl). Ao sobrepor as coordenadas desses corpos sobre o mapa ternário, não se notou qualquer correlação entre estes corpos e as anomalias radiométricas com médias contagens de potássio e baixos teores de tório e urânio (Fig. 14).

O corpo da porção sul do Batólito Santa Helena apresenta uma faixa com altas contagens dos três elementos localizada na sua borda ocidental e estendendo-se para SE (Fig. 16). Na porção meridional do batólito são observadas seis regiões internas ao corpo com coloração vermelho-escuro (numeradas de 3 a 8 no mapa ternário da Fig. 16), indicando assim concentrações dos radioelementos diferentes do resto do batólito. De fato, ao confrontar as coordenadas desses corpos com os mapas das contagens individuais de cada canal, observa-se que os corpos possuem contagem média a baixa de potássio e baixas contagens de urânio e tório (Fig. 14).

Ao comparar o mapa do modelo digital de terreno (Fig. 13) com o mapa de contagem dos radioelementos (Fig. 14), nota-se que o aumento das contagens de tório e urânio, observados na porção oeste do batólito, está associado às áreas de maior elevação topográfica do mesmo. Considerando que o potássio apresenta uma mobilidade muito maior do que os demais radioelementos, é possível que este tenha sido lixiviado das regiões com as maiores altitudes, enquanto que o tório e o urânio, muito menos moveis, tenham permanecido na rocha fonte.

A composição mineralógica do granito é caracterizada pela presença de K-feldspato e quartzo, enquanto que o anortosito possui o plagioclásio como constituinte principal. Sendo assim, a diferenciação entre a porção norte e sul do batólito, evidente principalmente em relação às contagens de potássio (Fig. 14-1), pode ser explicada por uma diferenciação bimodal do magma e posterior formação das suítes granítica (ao norte) e anortosítica (ao sul), como proposto por Geraldes (1996). Entretanto, o intervalo de susceptibilidade magnética associada ao granito e ao anortosito é extremamente parecido, não sendo possível utilizar tal propriedade física para caracterizar a divisão com exatidão. É importante ressaltar também a necessidade de visitas ao local para verificar se há um volume expressivo de anortositos que justifiquem a divisão em duas suítes, ou se a diferença na resposta geofísica entre as porções norte e sul do batólito não está relacionada a uma diferenciação suave do magma, a qual não implica necessariamente em uma divisão do corpo em duas suítes diferentes.

Os contornos das fácies mineralógicas definidas por Ruiz (2005) para o Batólito Santa Helena (Fig. 12) foram sobrepostos ao mapa de distribuição ternária dos radioelementos (Fig. 16). A partir da comparação entre estes é possível notar uma razoável correspondência entre a fácies III com a porção NE do batólito, enquanto a fácies II, localizada na borda oeste do corpo, estaria totalmente inserida na região com altas contagens dos três elementos. Os limites entre as fácies não foram reconhecidos em campo pelo autor citado, não sendo possível correlacioná-los com os dados gamaespectrométricos com precisão. Não foi possível também identificar diferenciação clara nos dados radiométricos associados à diferenciação entre a fácies I e IV.

A noroeste do batólito é observada uma anomalia radiométrica com média a alta contagem de potássio, baixas a médias contagens de tório e altas contagens de urânio (Fig. 13). As contagens de potássio e tório apresentam um gradual aumento de oeste para leste. A anomalia radiométrica está associada ao granito São Domingos descrito por Menezes et al. (1993, apud Ruiz 2005), o qual intrude a borda norte do batólito (Fig. 12). A partir da sobreposição dos contornos geológicos ao mapa ternário (Fig. 16) e ao mapa de contagens total (Fig. 15) nota-se que as altas contagens dos radioelementos associadas a este granito (principalmente potássio e urânio) apresentam limites diferentes dos especificados para este corpo.

Ao confrontar o mapa ternário (Fig. 16) e de contagem dos radioelementos (Fig. 14) com o mapa topográfico da região (Fig. 13) nota-se que os altos radiométricos de potássio e urânio observados na região sudoeste e leste do granito São Domingos estão associados a altos topográficos. A configuração permite concluir que os radioelementos associados ao granito estão sendo erodidos, e posteriormente depositados ao longo do córrego localizado na parte oeste da intrusão. Essa deposição de sedimentos, ricos em $\mathrm{Ke} \mathrm{U}$, justifica as altas contagens desses elementos observadas ao longo da zona de aluvião do córrego, mesmo em regiões distantes do corpo.

A partir da interpretação do mapa ternário dos radioelementos (Fig. 16) foi confeccionado o mapa litogeofísico para a região do batólito (Fig. 17), o qual consiste na associação de uma cor específica para o teor de emissão de raios gama observada para os três radioelementos. Sobre esse mapa 
foram sobrepostos tanto o contorno do Batólito Santa Helena e do granito de São Domingos definidos por Ruiz (2005 - Fig. 12) assim como os definidos neste trabalho a partir dos dados geofísicos.

Ao comparar os contornos, nota-se boa convergência entre os limites geológicos e o proposto a partir dos dados geofísicos em relação às dimensões principais do batólito, com direção essencialmente N-S.

A diferença observada entre ambos os contornos analisados para as regiões leste e oeste do batólito (Fig. 15 e 17) pode ser explicada pela erosão de radioelementos em áreas mais elevadas internas ao corpo e posterior deposição destes em áreas de baixo topográfico, externas aos limites da intrusão (Fig. 13 e 14). Considerando que a gamaespectrometria possui uma resposta mais superficial, esta deposição pode prejudicar a definição dos limites do corpo com precisão.

O Batólito Santa Helena é limitado a NE pela Zona de Cisalhamento Indiavaí-Lucialva. Nessa região observa-se uma diferenciação entre os limites propostos para o corpo (Fig. 15 e 17). Ao analisar o mapa topográfico (Fig. 13), nota-se que esta área é marcada por diversas falhas menores próximas à zona de cisalhamento, as quais podem ter condicionado a deposição de sedimentos ricos principalmente em tório e urânio erodidos da rocha fonte, justificando assim não apenas a diferença nos contornos como a presença de uma anomalia ciano, com direção aproximadamente N65W, observada para essa região no mapa ternário e litogeofísico (Fig. 16 e 17, respectivamente).

Também é possível observar uma diferenciação entre os contornos analisados referentes à parte sul do batólito, sendo que os dados radiométricos sugerem uma extensão maior para o corpo do que a observada para o mapa geológico. Assim como nas regiões leste e oeste, a diferença pode ser justificada pela deposição de radioelementos erodidos do batólito em regiões externas ao limite do corpo.

A leste do Batólito Santa Helena é observada uma região com altas a médias contagens de Th, médias contagens de U e baixas de K (Fig. 14 e 16). Essa assinatura radiométrica está associada à

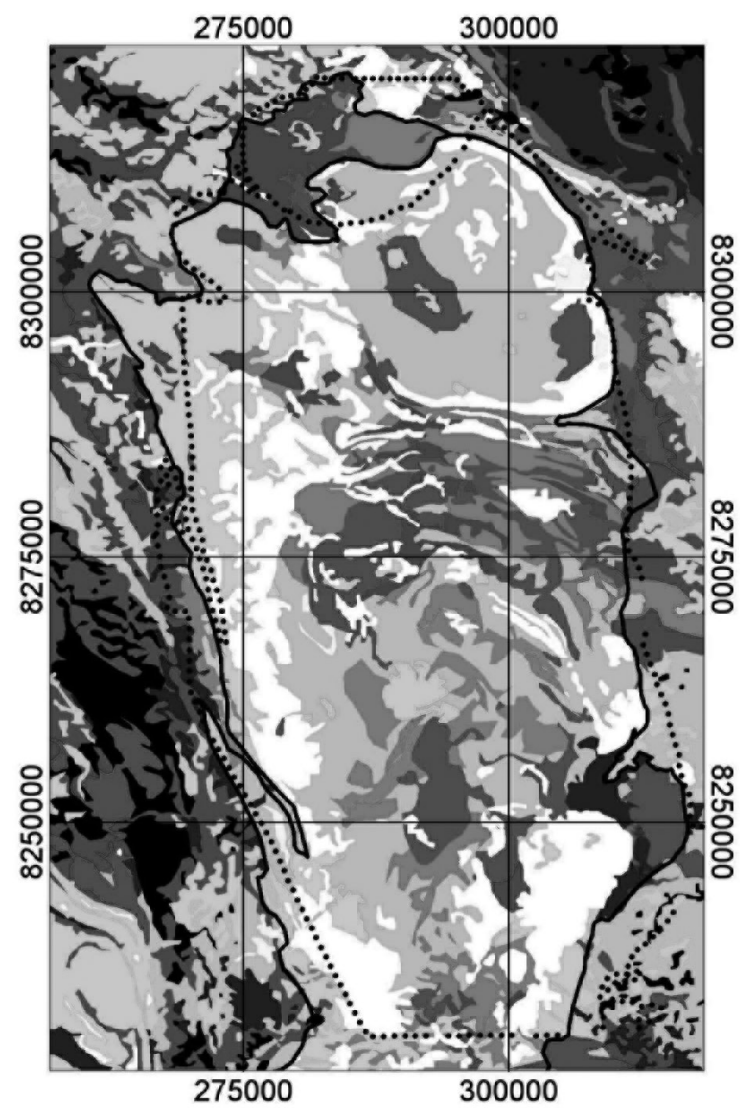

\section{LEGENDA}

\begin{tabular}{|c|}
\hline $\begin{array}{l}\text { Altas contagens de Th, baixas } \\
\text { contagens de } \mathrm{Ke} \mathrm{U}\end{array}$ \\
\hline $\begin{array}{l}\text { Médias contagens de Th, baixas } \\
\text { contagens de } \mathrm{Ke} \mathrm{U}\end{array}$ \\
\hline $\begin{array}{l}\text { Altas contagens de Th e } \mathrm{U} \\
\text { baixas de } \mathrm{K}\end{array}$ \\
\hline $\begin{array}{l}\text { Altas contagens de } \mathrm{Ke} \mathrm{Th} \text {, } \\
\text { baixas de } \mathrm{U}\end{array}$ \\
\hline $\begin{array}{l}\text { Altas contagens de } \mathrm{K} \text {, médias de } \\
\text { U e baixas de Th }\end{array}$ \\
\hline $\begin{array}{l}\text { Altas contagens de } \mathrm{K} \text {, médias de } \\
\mathrm{U} \text { e Th }\end{array}$ \\
\hline $\begin{array}{l}\text { Altas contagens de } U \text {, média de } \\
\text { K e baixas de Th }\end{array}$ \\
\hline $\begin{array}{l}\text { Altas contagens de } U \text {, médias de } \\
\mathrm{KeTh}\end{array}$ \\
\hline $\begin{array}{l}\text { Altas contagens de } \mathrm{K} \text {, baixas de } \\
\text { Th } \mathrm{e} U\end{array}$ \\
\hline $\begin{array}{l}\text { Médias contagens de K, baixas } \\
\text { de Th e U }\end{array}$ \\
\hline $\begin{array}{l}\text { Médias a baixas contagens de } \mathrm{K} \text {, } \\
\text { baixas de Th e } \mathrm{U}\end{array}$ \\
\hline Altas contagens de $\mathrm{K}$, Th e $\mathrm{U}$ \\
\hline Baixas contagens de $\mathrm{K}$, Th e U \\
\hline $\begin{array}{l}\text { Contorno do batólito de Santa } \\
\text { Helena e Granito São Domingos } \\
\text { (Ruiz, 2005) }\end{array}$ \\
\hline $\begin{array}{l}\text { Contorno do batólito de Santa } \\
\text { Helena e do Granito Săo Domingos } \\
\text { definido a partir dos dados de gama }\end{array}$ \\
\hline
\end{tabular}

Figura 17. Mapa litogeofísico confeccionado a partir da distribuição ternária dos radioelementos na região de estudo. A linha traço-ponto corresponde aos limites do batólito de Santa Helena definido por Ruiz (2005), enquanto que a linha pontilhada indica os limites deste corpo traçados a partir dos dados geofísicos 
Formação Jauru localizada nessa região (Fig. 12).

Na porção nordeste do Batólito Santa Helena, observa-se uma região com médio a baixo teor de K, e baixos teores de Th e U (Fig. 14), sendo caracterizada por tons mais escuros de vermelho nos mapas ternário e litogeofísico (Fig. 16 e 17). Essa resposta gamaespectrométrica está associada à Suíte Intrusiva Taquarussu e Complexo metavulcanosedimentar Pontes e Lacerda (Fig. 12), embora os limites entre estas não sejam evidentes nos mapas radiométricos.

Na porção oeste do batólito, onde se localiza a Zona de Cisalhamento Pindaiatuba, é possível observar uma região com altas a medias contagens de Th e U e médias a baixas contagens de K (Fig. 14), a qual apresenta faixas mais finas com direção aproximadamente N27W e teores médios a baixos de K e baixos de Th e U. A presença dessa zona de cisalhamento condicionou a deposição dos radioelementos ao longo da unidade litológica sobre a qual ela se localiza (Formação Fortuna - Fig. 12), dando assim o aspecto "listrado". Essa litologia faz fronteira ao sul com o Complexo metavulcanosedimentar Rio Alegre, o qual é caracterizado por apresentar baixas contagens de $\mathrm{K}$ e média a baixa de Th e U (Fig. 14 e 16).

\section{2 - Complexo Alcalino-Carbonatítico de Tapira (MG)}

\subsection{1 - Geologia}

O complexo de Tapira intrude as rochas do Cinturão Móvel Brasília, adjacente ao Cráton do São Francisco. Nesta região, a Faixa Brasília exibe um conjunto de três escamas empurradas sobre o Grupo Bambuí (marcado por filitos com lentes métricas de mármores cálcicos, sendo as condições metamórficas de fácies xisto verde inferior, na zona da clorita), delimitadas por falhas de cavalgamento e com características litológicas distintas (Silva et al. 2006). A constituição litológica destes domínios é:

1. Escama Inferior (Grupo Canastra): apresenta na base quartzo-muscovita, xistos intercalados por muscovita xistos, que em direção ao topo passam gradativamente a grafita-muscovita xistos. Essas rochas são sobrepostas por quartzo-muscovita xistos, com intercalações de quartzitos. No topo dessa escama ocorrem quartizitos puros a micáceos com intercalações de quartzos xistos. As condições metamórficas são de fácies xisto verde inferior médio (zona da clorita e da biotita).

2. Escama intermediária (Grupo Canastra): a base da escama é marcada por granada-grafita-muscovita xistos de granulação fina, intercalados a xistos grafitosos e granada-biotita-muscovita xistos. Estes são sobrepostos por granada-grafita xistos, que passam gradativamente a granada-mica xistos pouco grafitosos. No topo dessa escama ocorrem quartzitos com intercalações métricas de quartzo-xistos, muscovita-xistos e quartzitos micáceos. As condições metamórficas são de fácies xisto verde superior (zona da granada).

3. Escama Superior (Grupo Araxá): o litotipo mais frequente é granada-mica xisto, com camadas métricas de granada-quartzo xistos e rochas meta-ultramáficas. As condições metamórficas são de fácies anfibolito inferior.

A Figura 18 representa um esboço da geologia na região da intrusão alcalino-carbonatítica de Tapira.

O complexo de Tapira é uma chaminé ultramáfica-alcalina-carbonatítica com aproximadamente $35 \mathrm{~km}^{2}$ de área, tendo uma extensão de aproximadamente $7.4 \mathrm{~km}$ no eixo NE e $6.0 \mathrm{~km}$ na direção NW. Segundo Brod (1999), a intrusão deformou a rocha encaixante do grupo Canastra, provocando o desenvolvimento local de disjunção colunar em quartizitos e produziu cristalização de piroxenito sódico e feldspato em uma auréola de fenitização restrita (Fig. 2).

O Complexo Alcalino de Tapira é formado por diversas intrusões de rochas plutônicas silicáticas e, em menor quantidade, por carbonatitos. A série plutônica consiste na maioria de bebedouritos (clinopiroxenito alcalino com biotita), com sienitos subordinados e rara presença de dunitos (Brod et al. 2005). Segundo Brod et al. (2000), o magma primitivo desse complexo é ultrapotássico com uma forte afinidade com kamafugitos e sofreu diferenciação durante sua ascensão, antes de sua intrusão.

Brod et al. (2004) associam o manto de intemperismo em Tapira a concentrações de titânio, fosfato, nióbio, terras raras (ETR) e vermiculita. Segundo esses autores, a geologia da mina instalada em Tapira consiste de material intemperizado proveniente principalmente de piroxenitos. 


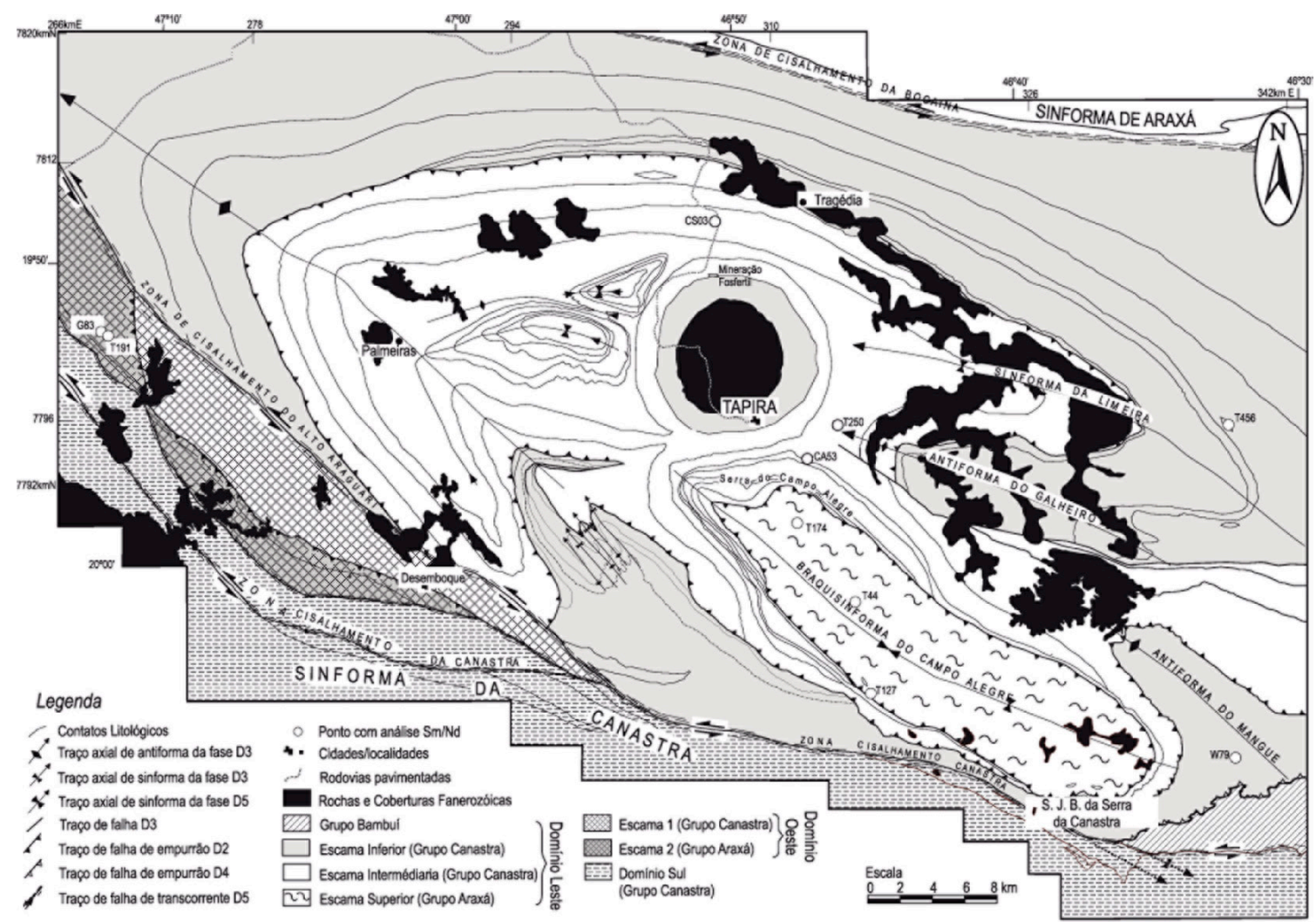

Figura 18. Mapa geológico simplificado da região de Tapira, Minas Gerais. Modificado de Silva (2003). No mapa está indicado o Complexo Alcalino de Tapira, assim como a localização da mineradora Fosfértil e outras localidades na região

\subsection{2 - Resultados da Análise Gamaespectrométrica}

Os mapas das contagens individuais dos elementos radiométricos, assim como das razões entre os elementos e os mapas ternários para a região do Complexo Alcalino de Tapira estão dispostos nas Figuras 10 e 11. Para uma melhor análise do mapa ternário com padrão RBG, este é apresentado em maior escala na Fig. 19.

Ao analisar os mapas com a distribuição das contagens de Th e U (Fig. 10 B e C), nota-se uma forte anomalia com altas contagens desses elementos associada à alcalina de Tapira (indicada pelo número 1 no mapa ternário - Fig. 19). O mapa com a distribuição das contagens de K (Fig. $10 \mathrm{~A})$, entretanto, apresenta um baixo radiométrico associado a esse complexo. Essa resposta condiz com o esperado para intrusões ígneas básicas aflorantes (Dickson \& Scott 1997), como é o caso da rocha alcalina.

$\mathrm{Na}$ parte norte do Complexo Alcalino de Tapira, nota-se a presença de três regiões com baixas contagens dos três elementos. Essas regiões podem ser explicadas pela presença de lagoas de rejeitos gerados pela mineradora Fosfértil, localizada nessa área.

Ao comparar o mapa ternário (Fig. 19) com o mapa geológico (Fig. 18) da região de Tapira é possível analisar a resposta radiométrica das principais estruturas e contatos geológicos da área estudada.

A sinforma de Araxá, localizada ao norte do mapa (indicada pela letra A - Fig. 19), apresenta contagens mais elevadas de tório e urânio ao longo dos seus limites, em contraste com a resposta radiométrica observada para a escama Intermediária do Grupo Canastra com a qual faz contato.

A escama superior do Grupo Canastra (B - Fig. 19), onde se localiza a branquisforma de Campo Alegre, região sul do mapa, possui baixas contagens dos três elementos, apresentando assim baixa resposta radiométrica. Porém tanto ao sul da branquisforma quanto ao norte são observadas anomalias com altas contagens de tório e urânio provavelmente associadas à presença de rochas e coberturas fanerozoicas.

Anomalias de tório e urânio são observa- 


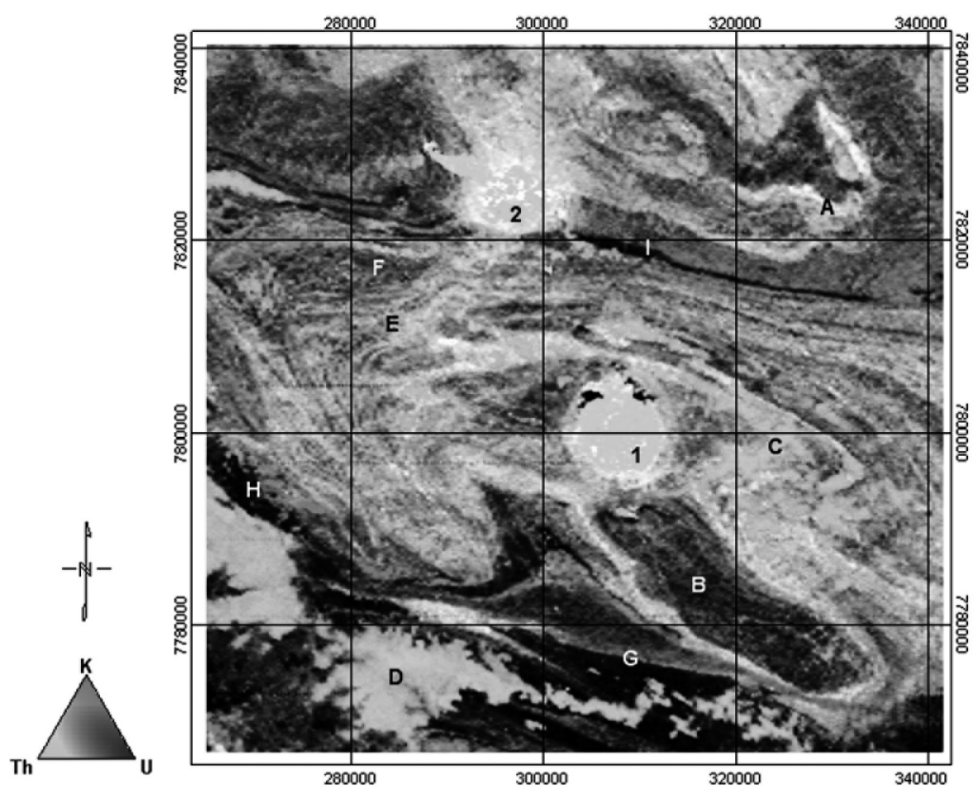

Figura 19. Mapa radiométrico ternário com coloração $(R, G, B)=(K, T h$, $U)$. Os índices 1 e 2 indicam a localização dos complexos alcalinos de Tapira e Araxá, respectivamente. A - Sinforma de Araxá, B - escama superior do Grupo Canastra, C e D - rochas e coberturas fanerozoicas, $E$ - escama intermediária e $F$ - escama inferior do Grupo Canastra, $\mathrm{G}$ - Zona de Cisalhamento da Canastra, $\mathrm{H}$ - Zona de Cisalhamento do Alto Araguari, I - Zona de Cisalhamento da Bocaina

das também em outros pontos do mapa ternário, coincidindo com a localização da unidade litológica identificada como sendo composta por rochas e coberturas fanerozoicas discriminadas no mapa geológico (Fig. 18). Esta assinatura radiométrica pode ser observada em pequenas áreas esparsas a leste e norte da alcalina de Tapira (letra C), assim como na porção sudoeste do mapa, onde apresenta uma maior extensão (letra D - Fig. 19).

Considerando a assinatura radiométrica associada a essa cobertura, o mapa ternário (Fig. 19) evidencia a presença de áreas com essa cobertura que não aparecem indicadas no mapa geológico da região (Fig. 18), principalmente na parte ao norte e a leste do complexo alcalino-carbonatítico de Tapira. Para confirmar a presença das coberturas nas regiões identificadas seriam necessárias observações "in loco".

O contato geológico entre as escamas intermediária (letra E) e inferior (letra F- Fig. 19) do Grupo Canastra, localizadas na porção oeste do mapa, é bem evidente e caracterizam-se principalmente pela diferença observada para as contagens dos três elementos ao longo da unidade litológica, sendo as maiores contagens observadas para a escama intermediária.

A distribuição dos radioelementos ao longo da escama intermediária do Grupo Canastra (letra E- Fig. 19) apresenta uma resposta característica de zonas de dobras. Esse padrão deve-se principalmente à presença de inúmeras falhas observadas nessa região, geradas devido a diversos dobramentos. Entre esses dobramentos podem ser citados a Sinforma de Limeira, Antiforma do Galheiro e Antiforma do Mangue, a oeste do mapa (Fig. 18).

Na porção sul do mapa observa-se o claro contraste entre as altas contagens dos radioelementos amostradas para as litologias do Domínio Leste em relação às baixas contagens dos Domínios Oeste e Sul do Grupo Canastra (Fig. 19). Essa região é caracterizada por ser uma zona de falha transcorrente da fase D5 (Silva 2003). O contraste entre esses domínios fica mais evidente principalmente ao sul da branquisforma de Campo Alegre, na parte leste da Zona de Cisalhamento da Canastra (letra G), e na porção oeste do contato, onde se localiza a Zona de Cisalhamento do Alto Araguari (letra H - Fig. 19).

Ao norte do mapa ternário (Fig. 19) nota-se a presença de um lineamento cruzando horizontalmente o mapa, caracterizado por apresentar baixas contagens dos três elementos. Este lineamento está associado a uma zona de falhas transcorrentes, onde se localiza a Zona de Cisalhamento da Bocaina (indicada pela letra I, neste mapa).

\section{7 - Conclusão}

Apesar da pouca penetrabilidade, a gamaespectrometria é, comprovadamente, uma ferramenta muito útil para caracterização de diferentes tipos litológicos (ex. granitos indiferenciados), identificação de possíveis novos alvos exploratórios, analise da ocorrência de hidrotermalismo e, principalmente a partir dos novos levantamentos realizados, para indicar os limites geográficos de uma unidade litológica com mais precisão.

A análise dos dados aerogamaespectrométricos referentes à região do Batólito Santa Helena 
(MT) permitiu identificar duas assinaturas bem distintas entre a parte setentrional e meridional desse corpo, com a parte norte apresentando contagens de potássio mais elevadas e anomalia magnética negativa enquanto a parte sul é caracterizada por contagens um pouco menores, principalmente de potássio.

Tanto na parte norte quanto na parte sul do batólito Santa Helena são observadas anomalias radiométricas caracterizadas por teores de médio a baixo de potássio, e baixas contagens de tório e urânio, as quais podem estar relacionadas à presença de um corpo granítico tardio com cerca de $1 \mathrm{Ga}$. identificado por Ruiz (1992, apud Geraldes et al. 2001). Geraldes et al. (2001), por sua vez, identificam diversos diques de granitóides que intrudem o batólito e podem estar correlacionados com as demais anomalias radiométricas observadas principalmente na parte sul do batólito. É, porém, importante ressaltar a necessidade de observações "in loco" para certificar-se dessa correlação.

A partir da analise mais regional dos mapas gamaespectrométricos foi possível identificar a assinatura radiométrica associada às litologias circundantes ao batólito de Santa Helena, entre elas: Complexo Serra do Baú, Formação Jauru e Grupo Aguapeí. Essa análise permitiu identificar também uma anomalia radiométrica com altas contagens de tório e urânio e baixas contagens de potássio, mais alongada com inclinação de aproximadamente N65W, associada à Zona de Cisalhamento Indiavaí-Lucialva.

O complexo alcalino-carbonatítico de Tapira (localizado em Minas Gerais, apresentado no primeiro estudo de caso) possui uma resposta gamaespectrométrica característica, sendo fácil sua identificação nos mapas radiométricos gerados. Essa intrusão está localizada numa região marcada pela presença de falhas de calvagamento do Cinturão Móvel Brasilia. A disposição das falhas ao longo da região e a atuação do intemperismo e hidrografia local, afetam drasticamente a distribuição dos elementos radiométricos ao longo das litologias, gerando assim uma resposta gamaespectrométrica única para a região.

A escama intermediária (Grupo Canastra) é identificada no mapa geológico como tendo uma composição homogênea, entretanto a resposta gamaespectrométrica dessa litologia apresenta um comportamento heterogêneo com alternância de áreas com diferentes contagens dos elementos radiométricos, condicionados pela presença de diversas falhas ao longo dessa litologia.

\section{Agradecimentos}

CODEMIG e CPRM forneceram os dados aéreos. $\mathrm{CNPq}$ forneceu o suporte financeiro nos processos 142673/2011-0 e 141587/2013-0. Os autores agradecem o apoio dessas entidades.

\section{Referências}

Biondi J.C., Bartoszeck M.K., Vanzela A.G. 2001. Análise da favorabilidade para depósitos de caulim na bacia de Campo Alegre (SC). Rev. Bras. Geoc., 31(1):59-66.

Boyle R.W. 1982. Geochemical prospecting for thorium and uranium deposits. Amsterdan: Elsevier. (Developments in Economic Geology, 16).

Brod J.A. 1999. Petrologia e geoquímica do complexo de Tapira, estado de Minas Gerais. Reino unido: University of Durham. (Tese Dout.).

Brod J.A., Gaspar J.C., Diniz-Pinto H.S., Junqueira-Brod T.C. 2004. Excursão 1. Geologia e mineralização dos complexos alcalino-carbonatíticos da Província Ígnea do Alto Paranaíba. In: Congr. Bras. Geol., 42, Araxá, 2004. Excursão... Araxá: SBGeo.

Brod J.A., Gaspar J.C., Diniz-Pinto H.S., Junqueira-Brod T.C. 2005. Spinel chemistry and petrogenetic processes in the Tapira Alkaline-Carbonatite Complex, Minas Gerais, Brasil. Rev. Bras. Geoc., 35(1):23-32.

Brod J.A., Gibson S.A., Thompson R.N., JunqueiraBrod T.C., Seer H.J., Moraes L.C.de, Boaventura G.R. 2000. The kamafugite-carbonatite association in the Alto Paranaíba Igneous Province, southeastern Brazil. Rev. Bras. Geoc., 30(3):404-408.

Cotis D.S., Mantovani M.S.M., Ribeiro V.B., Santos R.P.Z. Geophysical Characterization of Magnetic Anomaly Jauru River (Mato Grosso, Brazil). In: Intern. Congr. Brazilian Geophys. Soc., 13, 2013. Anais... Rio de Janeiro: 2013.

Cox K.G., Bell J.D., Pankhurst R.J. 1979.The interpretation of igneous rocks. Londres: George Allen \& Unuwin. 450p.

Carrino T.A., Souza Filho C.R. de, Leite E. P. 2007. Avaliação do uso de dados aerogeofísicos para mapeamento geológico e prospecção mineral em terrenos intemperizados: o exemplo de Serra Leste, província mineral de Carajás. Rev. Bras. Geof., 25(3):307-320.

Conceição F.T., Bonotto D.M. 2003. Use of U-isotope disequilibrium to evaluate the weathering rate and fertilizer-derived uranium in São Paulo state, Brazil. Environmental Geology, 44:408-418.

Dickin A.D. 1995. Radiogenic Isotope Geology. Cambridge: Cambridge Univ. Press. 490p.

Dickson B.H., Bailey R.C., Grasty R.L. 1981. Utilising multichannel airborne gamma-ray spectra. Canadian J. Earth Sci., 18:1793-1801. 
Dickson B.L., Clark G.J., McGregor B.J. 1979. Technique for correcting for over-burden effects in ground level radiometric surveys of uranium ore bodies. Geophysics, 44:89-98.

Dickson B.L., Scott K.M. 1997. Interpretation of aerial gamma-ray surveys - adding the geochemical factors. AGSO J. Australia Geology \& Geophysics. 17(2):187-200.

Faure G. 1997. Principles and applications of geochemistry. Nova Iorque: Prentice Hall. 589p.

Foote R.S. 1968. Improvement in airborne gamma radiation data analyses for anomalous radiation changes. In: Simp. sobre uso de Técnicas Nucleares na Prospecção e Desenvolvimento de Recursos Minerais. 1968. Anais... Buenos Aires.

Fornazzari Neto L., Ferreira F.J.F. 2003. Gamaespectrometria integrada a dados exploratórios multifonte em ambiente SIG aplicada à prospecção de ouro na folha Botuverá, SC. Rev.Bras.Geoc. 33(2-Supl.):197-208.

Geraldes M.C., Van Schmus W.R., Condie K.C., Bell S., Teixeira W., Babinski M. 2001. Proterozoic geologic evolution of the SW part of the Amazonian Craton in Mato Grosso state, Brazil. Precambrian Research, 111: 91-128.

Gnojek I., Prichystal A. 1985. A new zinc mineralization detected by airbone gamma-ray spectrometry in Northern Moravia (Czechoslovakia). Geoexploration. 23(4):491-502.

Grasty R.L., Willes P.G., Kooyman R. 1988. Background measurement in gamma-ray surveys. Canada: Energy, Mines, and Resources of Canada. 31p.

Gunn P.J. 1998. Interpretation of airbone magnetic and radiometric surveys. Course. Camberra: AGSO Australian Geological Survey Organisation. 150p.

IAEA. 1991. Airborne gamma ray spectrometer surveying. Technical Reports Series $n^{\circ} 323$. Viena: Intern. Atomic Energy Agency.

IAEA. 2003. Guidelines for radioelement mapping using gamma ray spectrometry data. Viena: Intern. Atomic Energy Agency. 179 p.

Jost H., Fuck R.A., Dantas E.L., Rancan C.C., Rezende D.B., Santos E., Portela J.F., Mattos L., Chiarini M.F.N., Oliveira R.C., Silva S.E. 2005. Geologia e geocronologia do complexo de Uvá, bloco arqueano de Goiás. Rev. Bras. Geoc. 35(4):559-572.

Kaplan I. 1955. Nuclear Physics. Londres: Addison-Wesley Publ. Co. 609p.

Langmuir D., Herman J.S. 1980. The mobility of thorium in natural waters at low temperatures. Geochim. Cosmoch. Acta. 44:1753-1766.

Lüning S., Kolonic S. 2003. Uranium spectral gamma-ray response as a proxy for organic richness in black shales: applicability and limitations. Journal of Petroleum Geology. 26(2):153-174.

Minty B.R.S. 1988. A review of airborne gamma-ray spectrometric data-processing techniques. Canberra: Australian Gov. Publ. Service. 48 p.

Nielson D.L., Linpei C., Ward S.H. 1990. Gamma-
Ray Spectrometry and radon emanometry in envitonmental geophysics. In: Stanley H. Ward. eds. 1990. Geotechnical and environmental geophysics. Edited by the Society of Exploration Geophysicists. p. 219-250.

Ribeiro V.B.; Mantovani M.S.M. 2012. Contribuição geofísica ao estudo do Batólito Granítico Santa Helena, sudoeste do Cráton Amazônico. Geologia USP Série Cientifica, 12(2):65-82.

Ribeiro V.B., Louro V.H.A., Mantovani M.S.M. 2013. Geophysical study of the Sertãozinho, Rio Aguapeí and Nova anomalies (SW of Mato Grosso, Brazil). In: Intern. Congr. Brazilian Geophys. Soc., 13, 2013. Anais... Rio de Janeiro. SBGf.

Rudnick R., Gao S. 2004. Composition of the continental crust. In: Holland H.D., Turekian N.N. eds. Treatise on geochemistry. Oxford: Elsevier Pergamon. 3:1-64.

Ruiz A.S. 1992. Contribuição a Geologia do Distrito da Cachoeirinha, MT. São Paulo: Univ. São Paulo. 98p. (Dados inéditos).

Saunders D.F., Terry S.A., Thompson C.K. 1987. Test of national uranium resource evaluation gamma-ray spectral data in petroleum reconnaissance. Geophysics, 52(2):1547-1556. Novembro 1987.

Silva C.H., Simões L.S.A., Krymsky R., Macambira M.J.B. 2006. Proveniência e idade do metamorfismo das rochas da Faixa Brasília, na região de Tapira (SW de Minas Gerais). Geologia USP Série Cientifica, 6(1):53-66. Julho 2006.

Silva C.H. 2003. Evolução geológica da Faixa Brasília na região de Tapira, sudoeste de Minas Gerais. 2003. Rio Claro: Inst. Geoc. Ciências Exatas, UNESP. 196p. (Tese Dout.).

Silva L.G. 2006. Metodologia geofísica para discriminação de corpos intrusivos na província alcalina do Alto Parnaíba, MG. Brasília: Inst. Geoc., UnB, 78p. (Dissert. Mestr.).

Telford W.M., Geldart L.P., Sheriff R.E. 1990. Applied geophysics. 2 ed. Nova Iorque: Univ. Cambridge. 770p.

Ulbrich H.H.G.J., Ulbrich M.N.C., Ferreira F.J.F., Alves L.S., Guimarães G.B., Fruchting A. 2009. Levantamentos Gamaespectrométricos em Granitos Diferenciados. I: Revisão da Metodologia e do Comportamento Geoquímico dos Elementos K, Th e U. Geologia USP: Série Cientifica, 9(1):33-53.

Vasconcellos R.M. 1994. Geofisica em levantamentos geológicos no Brasil. Rio de Janeiro: Companhia de Pesquisa e Recursos Minerais, CPRM. 165 p.

Vasconcelos M.A.R., Leite E.P., Crósta A.P. 2012. Contributions of gamma-ray spectrometry to terrestrial impact crater studies: the example of Serra da Cangalha, northeastern Brazil. Geophys. Res. Lett. doi:10.1029/2011GL050525, in press. 2012.

Wilford J.R., Bierwirth P.N., Craig M.A. 1997. Application of airborne gamma-ray spectrometry in soil/ regolith mapping and applied geomorphology. Journal of Australian Geology E Geophysics, 17(2): 201-216. 